\title{
In situ behaviour of a stiff layered clay subject to thermal loading: observations and interpretation
}

\author{
A. GENS ${ }^{*}$, J. VAUNAT ${ }^{*}$, B. GARITTE* and Y. WILEVEAU ${ }^{\dagger}$
}

The paper presents an interpretation of an in situ heating test carried out on Opalinus clay in the Mont Terri underground laboratory. Opalinus clay is a stiff, strongly bedded, Mesozoic clay of marine origin. When subjected to thermal loading, saturated stiff clays exhibit a strong pore pressure response that significantly affects the hydraulic and mechanical behaviour of the material. The observations gathered in the in situ test have provided an opportunity to examine the integrated thermo-hydromechanical (THM) response of this sedimentary clay. Coupled THM numerical analyses have been carried out to provide a structured framework for interpretation, and to enhance understanding of THM clay behaviour. Numerical analyses have been based on a coupled theoretical formulation that incorporates a constitutive law especially developed for this type of material. The law includes degradation of bonding by damage. By performing three-dimensional computations, it has been possible to incorporate anisotropy of material parameters and of in situ stresses. The $3 \mathrm{D}$ simulation has proved able to furnish a satisfactory representation of the development of the in situ test and of the main observed patterns of behaviour. A sensitivity analysis has also been carried out to examine the potential effect of various key or uncertain parameters. The critical examination of test observations and the results of the numerical analyses have allowed the classification, by differing degrees of significance, of the various coupled phenomena present in the problem.

KEYWORDS: anisotropy; clays; in situ testing; numerical modelling; radioactive waste disposal; temperature effects
Cet article présente une interprétation d'un essai de chauffage in situ sur une argile Opalinus dans le laboratoire sous-terrain de Mont Terri. L'argile Opalinus est une argile mésozoïque ferme et fortement stratifiée d'origine marine. Lorsque les argiles fermes saturées sont soumises à une charge thermique, on observe une forte réponse de pression interstitielle qui affecte significativement le comportement hydraulique et mécanique du matériau. Les observations recueillies dans l'essai in situ ont permis d'examiner la réponse thermo-hydromécanique (THM) intégrée de cette argile sédimentaire. On a effectué des analyses numériques THM couplées pour fournir un cadre structuré à l'interprétation et pour améliorer la compréhension du comportement THM de l'argile. Les analyses numériques sont basées sur une formulation théorique couplée qui incorpore une loi constitutive spécialement développée pour ce type de matériau. La loi inclut la dégradation de la cimentation par détérioration. Grâce à des calculs tridimensionnels, on a pu incorporer l'anisotropie des paramètres matériels et des contraintes in situ. La simulation tridimensionnelle a permis de fournir une représentation satisfaisante du développement de l'essai in situ et des principaux modes de comportement observés. On a également effectué une analyse de sensibilité pour examiner l'effet potentiel de divers paramètres clés ou incertains. Grâce à l'examen critique des observations des essais et aux résultats des analyses numériques, on a pu effectuer la classification des divers phénomènes couplés présents, par divers degrés de signification.

\section{INTRODUCTION}

Stiff sedimentary clays provide the geological background to many civil engineering projects. In recent years, interest in these types of material has increased, because they are being considered as potential host geological media for underground repositories of high-level radioactive waste (Gens, 2003). They exhibit favourable characteristics, such as low permeability, a degree of self-healing capacity when fractured, significant retardation properties for solute transport, and no foreseeable economic value. Possible shortcomings are the likely need for support of the excavated openings, and sensitivity to chemical actions and to desaturation caused by ventilation. High-level radioactive waste is heatemitting. Therefore the use of stiff sedimentary clays in this type of application brings to the fore the thermal response of this type of material and, especially, the interaction of

Manuscript received 9 May 2006; revised manuscript accepted 8 January 2007.

Discussion on this paper closes on 1 August 2007, for further details see p. ii.

* Department of Geotechnical Engineering and Geosciences, Technical University of Catalonia, Spain.

${ }^{\dagger}$ ANDRA, Chatenay Malabry, France. thermal phenomena with hydraulic and mechanical behaviour.

The possible use of these types of clay as geological hosts for radioactive waste has prompted the construction of several underground laboratories. They include: the Hades laboratory in Mol (Belgium), excavated in Boom clay; the Meuse/Haute Marne laboratory of Eastern France, sited in a thick stratum of Callovo-Oxfordian mudstone; and the Mont Terri laboratory of northern Switzerland, constructed in Opalinus clay. Underground laboratories allow, by the performance of appropriate in situ tests, observation of the clay response in complex situations that mimic some of the conditions likely to be encountered in a deep geological repository. In particular, special attention is paid to the coupled thermo-hydro-mechanical (THM) behaviour of the potential host clay.

The existence of underground laboratories offers both an opportunity and a challenge. The opportunity lies in the availability of extensive experimental studies, both in the laboratory and in situ, that provide a level of characterisation of the stiff sedimentary clay much higher than that normally available in a conventional civil engineering project. The challenge lies in the need to achieve a good understanding of the generalised behaviour of these clays when subjected 
to complex demands in a natural environment. Generally, numerical analyses are an essential tool towards achieving such an understanding.

Various in situ heating tests have been performed involving the observation of the response of natural sedimentary clay. For instance, in the Hades laboratory the following experiments have been performed: the CACTUS test, the ATLAS test and the CERBERUS test (Picard et al., 1994; Bernier \& Neerdael, 1996; De Bruyn \& Labat, 2002). The results obtained in these tests have led to a better characterisation of the THM properties of the Boom clay formation. The CERBERUS test has also included radioactive material in the heating source to study the additional effects of radiation on material behaviour. In the Opalinus clay of the Mont Terri laboratory, the test HE-D has been performed, the results of which are examined and interpreted in this paper. Finally, in the Meuse/Haute Marne laboratory, an in situ heating test (TER) is under way at present. In all cases the sedimentary clays react to the temperature increase with a rise of pore water pressures and associated mechanical effects, although the specific features of the response naturally depend on the particular clay being tested. A good understanding of the resulting coupled THM behaviour is therefore necessary for a rational design of potential repositories.

This paper concentrates on the response of Opalinus clay, a stiff, layered Mesozoic clay, to thermal loading in the context of the HE-D in situ heating test performed in the Mont Terri underground laboratory. Special attention is given to the interplay between the thermal, hydraulic and mechanical aspects of the clay behaviour. Some geological information on Opalinus clay is given first, together with a summary of the properties relevant to the case considered. Opalinus clay exhibits a strongly bedded structure that results in a distinct anisotropy of several THM properties. The in situ stresses in the massif are also anisotropic. After the description of the material, an outline of the theoretical formulation used in subsequent analyses is presented. The in situ heating test is then described. The observations are interpreted using a $3 \mathrm{D}$ coupled thermo-hydro-mechanical (THM) analysis that accounts for the main features of the generalised clay behaviour, including its anisotropy. Associated 2D axisymmetric computations have been used as reference. Finally, a sensitivity analysis (using the axisymmetric model) has been carried out to achieve an enhanced understanding of the clay behaviour and a more specific identification of critical parameters and interacting phenomena.

\section{CHARACTERISTICS OF OPALINUS CLAY}

Opalinus clay is a stiff overconsolidated clay of Lower Aalenian age, corresponding to the Middle Jurassic. It is found in the Jura Mountains of Northern Switzerland. Its mineralogy consists mainly of sheet silicates (illite, illitesmectite mixed layers, chlorites, kaolinites), framework silicates (albites, K-feldspar), carbonates (calcite, dolomite, ankerite and siderite), and quartz (Bossart et al., 2002). There are three slightly different facies containing different mineral proportions: a shaly facies in the lower part of the deposit; a $15 \mathrm{~m}$ thick sandy-silty facies in the centre; and a sandy facies interstratified with the shaly facies in the upper part. The content of clay minerals may range from $40 \%$ to $80 \%$, depending on the facies. The clay was sedimented in marine conditions. Its pore water is highly mineralised, with total dissolved salts up to $20 \mathrm{~g} / \mathrm{l}$; this water contains a significant content of seawater millions of years old. Total thickness is about $160 \mathrm{~m}$. To place Opalinus clay in the context of the sedimentary clays present in other underground laboratories, a comparison of the typical values of some basic properties is presented in Table 1. Boom clay is a soil-like material with a relative large porosity in spite of the important burial depth. Opalinus clay and the CallovoOxfordian mudstone are indurated clays of low porosity and higher strength. Naturally, permeability is very low in all cases.

Opalinus clay behaviour has been intensely studied by means of laboratory and in situ experimental programmes. A synthesis of the main physical and geotechnical parameters is reported in Bock (2001). Based on this information, the reference values of a series of parameters together with their likely ranges have been listed in Table 2 . Note that some of the parameters have different values depending on the orientation of the material, reflecting the anisotropy caused by the intense bedding of the clay. When information is scarce, no range estimate has been quoted. The following additional remarks can be made.

(a) Reference elastic parameters have been based on measurements made in triaxial and uniaxial compression tests and on the results of field dilatometer tests.

(b) The reference shear strength parameters have been derived from laboratory triaxial tests. As strength depends on water content, only strength data for which the moisture content was within the range of the natural water content were considered.

(c) Permeability measurements were made on laboratory specimens and using in situ boreholes.

(d) Thermal dilation coefficient and Biot's coefficient are quite uncertain because the data on those parameters are limited.

The reference values have been used as a basis for estimating the parameters required in the numerical analyses reported below. However, alternative values have been adopted if information referring more specifically to the location of the in situ heating test was available.

Table 1. Some typical basic properties of Opalinus clay, Callovo-Oxfordian mudstone and Boom clay (Horseman et al., 1987; Baldi et al., 1991; Bernier et al., 1997; Harrington et al., 2001; Croisé et al., 2004; ANDRA, 2005; Coll, 2005; Wileveau, 2005; Bastiaens et al., 2006).

\begin{tabular}{|c|c|c|c|}
\hline & Opalinus clay & Callovo-Oxfordian mudstone & Boom clay \\
\hline $\begin{array}{l}\text { Dry density: } \mathrm{g} / \mathrm{cm}^{3} \\
\text { Calcite content: } \% \\
\text { Porosity: \% } \\
\text { Water content: } \% \\
\text { Young's modulus: } \mathrm{MPa} \\
\text { Unconfined compression strength: } \mathrm{MPa} \\
\text { Permeability: } \mathrm{m} / \mathrm{s}\end{array}$ & $\begin{array}{c}2 \cdot 22-2 \cdot 33 \\
6-22 \\
13 \cdot 5-17 \cdot 9 \\
4 \cdot 2-8 \cdot 0 \\
4000-10000 \\
4-22 \\
1-5 \times 10^{-13}\end{array}$ & $\begin{array}{c}2 \cdot 21-2 \cdot 33 \\
23-42 \\
<13 \\
<5 \cdot 5 \\
4000-5600 \\
20-30 \\
1-5 \times 10^{-13}\end{array}$ & $\begin{array}{c}1 \cdot 61-1 \cdot 78 \\
0-3 \\
>30 \\
>9 \cdot 5 \\
200-400 \\
2 \\
2-5 \times 10^{-12}\end{array}$ \\
\hline
\end{tabular}


Table 2. Reference parameters for Opalinus clay (Wileveau, 2005)

\begin{tabular}{|c|c|c|c|c|}
\hline & Parameter & Orientation* & Reference value & Range \\
\hline \multirow[t]{3}{*}{ Mineralogy } & Clay content: $\%$ & - & 62 & $44-80$ \\
\hline & Carbonate content: $\%$ & - & 14 & $6-22$ \\
\hline & Quartz content: \% & - & 18 & $10-27$ \\
\hline \multirow[t]{3}{*}{ Petrophysical properties } & Density, $\rho: \mathrm{g} / \mathrm{cm}^{3}$ & - & $2 \cdot 45$ & $\pm 0 \cdot 03$ \\
\hline & Water content, $w: \%$ & - & $6 \cdot 1$ & $\pm 1 \cdot 9$ \\
\hline & Porosity, $\phi: \%$ & & $15 \cdot 7$ & $\pm 2 \cdot 2$ \\
\hline \multirow[t]{13}{*}{ Mechanical properties } & Uniaxial compression strength, & Parallel & 10 & \pm 6 \\
\hline & $R_{\mathrm{c}}: \mathrm{Mpa}$ & Perpendicular & 16 & \pm 6 \\
\hline & Tensile strength, $R_{\mathrm{t}}: \mathrm{Mpa}$ & Parallel & 1 & - \\
\hline & & Perpendicular & $0 \cdot 5$ & - \\
\hline & Elastic modulus, $E$ : Mpa & Parallel & 10000 & \pm 3700 \\
\hline & & Perpendicular & 4000 & \pm 1000 \\
\hline & Poisson's ratio, $v$ & Parallel & $0 \cdot 24$ & - \\
\hline & & Perpendicular & $0 \cdot 33$ & - \\
\hline & Shear strength parameters & & & \\
\hline & $c^{\prime}: \mathrm{MPa}$ & Parallel & $2 \cdot 2$ & - \\
\hline & & Perpendicular & 25 & - \\
\hline & $\Phi^{\prime}:$ degrees & Parallel & $5 \cdot 0$ & - \\
\hline & & Perpendicular & 25 & - \\
\hline \multirow{4}{*}{$\begin{array}{l}\text { Thermal and thermomechanical } \\
\text { properties }\end{array}$} & Thermal conductivity, $\lambda: \mathrm{W} /(\mathrm{m} \mathrm{K})$ & Parallel & $2 \cdot 1$ & $\pm 10 \%$ \\
\hline & & Perpendicular & 0.995 & $\pm 10 \%$ \\
\hline & $\begin{array}{l}\text { Heat capacity of dry material at } \\
20^{\circ} \mathrm{C}, E_{\mathrm{s}}: \mathrm{J} /(\mathrm{kg} \mathrm{K})\end{array}$ & - & 800 & $\pm 10 \%$ \\
\hline & $\begin{array}{l}\text { Coefficient of linear thermal } \\
\text { expansion, } \alpha: \mathrm{K}^{-1}\end{array}$ & - & $2.6 \times 10^{-5}$ & - \\
\hline \multirow[t]{2}{*}{$\begin{array}{l}\text { Hydraulic and hydromechanical } \\
\text { properties }\end{array}$} & $\begin{array}{l}\text { Water permeability of sound clay, } \\
k: \mathrm{m} / \mathrm{s}\end{array}$ & - & $10^{-13}$ & $10^{-12}-10^{-14}$ \\
\hline & Biot's coefficient, $b$ & - & $0 \cdot 6$ & $0 \cdot 42-0 \cdot 78$ \\
\hline
\end{tabular}

* Orientation to bedding.

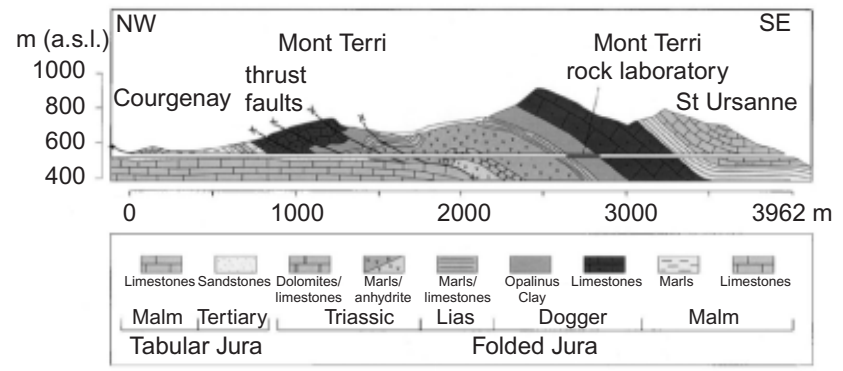

Fig. 1. Geological profile in vicinity of Mont Terri underground laboratory (Schaeren \& Norbert, 1989; Thury \& Bossart, 1999)

In the location of the Mont Terri laboratory (Fig. 1), overburden varies between $250 \mathrm{~m}$ and $320 \mathrm{~m}$ (it is estimated that overburden reached at least $1000 \mathrm{~m}$ in the past), and the closely spaced bedding dips at an angle of approximately $45^{\circ}$. Fig. 2 presents a picture of the Opalinus clay appearing on one side of a niche excavation, and shows clearly the strong layering of the material.

A significant number of measurements of the in situ stress have been made using different procedures (borehole slotter, undercoring, and hydraulic fracturing). They have been supplemented by geological observations and back-analysis of instrumented excavations. A synthesis of the information available is reported in Wermeille \& Bossart (1999) and in Martin \& Lanyon (2003). It appears that the most reliable data are provided by the undercoring method, yielding the estimation presented in Table 3. The following comments can be made.

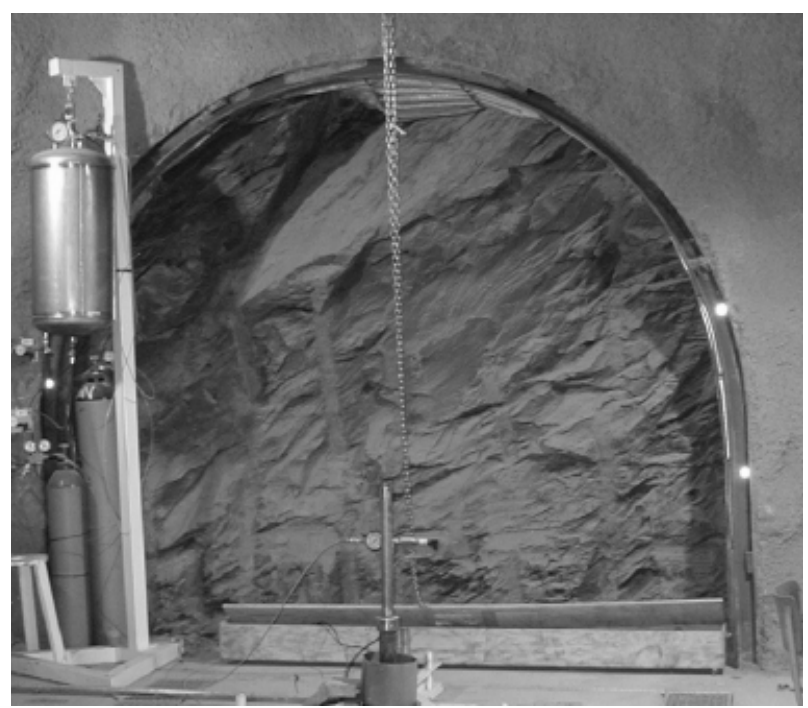

Fig. 2. View of Opalinus clay in an excavation at Mont Terri underground laboratory

(a) The major principal stress is subvertical, and corresponds approximately with the overburden weight.

(b) The magnitude of the intermediate principal stress obtained from the undercoring technique is consistent with the results from hydraulic fracture tests.

(c) The value of the minor principal stress is quite low, and is probably controlled by the presence of a deep valley to the SW of the laboratory. A low value of the minor 
Table 3. Estimated in situ stress system

\begin{tabular}{l|c|c|c|c}
\hline Principal stress & Orientation & Azimuth: degrees & Dip: degrees & Value: MPa \\
\hline Major, $\sigma_{1}$ & Subvertical & N210 & 70 & $6 \cdot 0-7 \cdot 0$ \\
Intermediate, $\sigma_{2}$ & Subhorizontal & N320 & 10 & $4 \cdot 0-5 \cdot 0$ \\
Minor, $\sigma_{3}$ & Subhorizontal & N50 & 20 & $2 \cdot 0-3 \cdot 0$ \\
\hline
\end{tabular}

principal stress is consistent with the small number of breakouts observed in vertical boreholes.

\section{THEORETICAL FORMULATION}

\section{Coupled phenomena and THM formulation}

When a thermal load is applied to a saturated porous material, hydraulic and mechanical effects ensue. A pore pressure rise will generally result from an increase of temperature due to the differential rate of expansion of the clay skeleton, solid phase and water. Indeed, in stiff materials, the increase in pore pressure may be very large and approach or even reach hydraulic fracture conditions. Material stresses and strains will be generated by both the change in temperature (thermal expansion) and the variation of pore pressure. Conversely, volume changes will affect the hydraulic regime via the well-understood consolidation process. Coupling towards the thermal problem also occurs via energy transport by water convection (hydraulic), and by energy loss associated with deformation processes (mechanical). Naturally, the strength and significance of each coupling relationship vary widely (Bai \& Abousleiman, 1997; Zimmerman, 2000).

Observations made during the test did not indicate any desaturation of the clay; it is presumed that the material has remained saturated throughout. Coupled THM formulations for saturated porous media have been proposed by several authors (e.g. Booker \& Savvidou, 1985; Katsube, 1988; Kurashige, 1989; Wang \& Papamichos, 1999; Kanj \& Abousleiman, 2005). They are usually applied to the derivation of analytical solutions and to the solution of simplified problems. Applications to field engineering cases are rare.

The theoretical THM formulation used herein is a particular case of the general formulation presented in Olivella et al. (1994) for saturated and unsaturated media. For space reasons, the formulation is only outlined in this section. Two phases are considered, solid (s) and liquid (1), corresponding to the two species mineral and water (w). Although, in this case, phases and species coincide, it is convenient to maintain the distinction for future generalisation.

The solution of a coupled THM problem requires the simultaneous solution of the following balance equations.

Balance of solid:

$$
\frac{\partial}{\partial t}\left[\rho_{\mathrm{s}}(1-\phi)\right]+\nabla \cdot\left(\mathbf{j}_{\mathrm{s}}\right)=0
$$

Balance of water mass:

$$
\frac{\partial}{\partial t}\left(\rho_{1} \phi\right)+\nabla \cdot\left(\mathbf{j}_{1}\right)=f^{\mathrm{w}}
$$

Balance of internal energy:

$$
\frac{\partial}{\partial t}\left[E_{\mathrm{s}} \rho_{\mathrm{s}}(1-\phi)+E_{1} \rho_{1} S_{1} \phi\right]+\nabla \cdot\left(\mathbf{i}_{\mathrm{c}}+\mathbf{j}_{\mathrm{Es}}+\mathbf{j}_{\mathrm{El}}\right)=f^{\mathrm{Q}}
$$

Equilibrium:

$$
\nabla \cdot \boldsymbol{\sigma}+\mathbf{b}=\mathbf{0}
$$

where $\phi$ is porosity; $\rho$ is density, $\mathbf{j}$ is total mass flux; $\mathbf{u}$ is the solid displacement vector; $\boldsymbol{\sigma}$ is the stress tensor; $\mathbf{b}$ is the body forces vector; $E$ is the specific internal energy; $\mathbf{i}_{\mathrm{c}}$ is the conductive heat flux; and $\mathbf{j}_{\mathrm{E}}$ is the energy flux due to mass motion.

Using the definition of material derivative,

$$
\frac{\mathrm{D}_{\mathrm{s}}(\bullet)}{\mathrm{D} t}=\frac{\partial(\bullet)}{\partial t}+\frac{\mathrm{d} \mathbf{u}}{\mathrm{d} t} \cdot \nabla(\bullet)
$$

equation (1) becomes

$$
\frac{\mathrm{D}_{\mathrm{s}} \phi}{\mathrm{D} t}=\frac{1}{\rho_{\mathrm{s}}}\left[(1-\phi) \frac{\mathrm{D}_{\mathrm{s}} \rho_{\mathrm{s}}}{\mathrm{D} t}\right]+(1-\phi) \nabla \cdot \frac{\mathrm{d} \mathbf{u}}{\mathrm{d} t}
$$

Now, the solid mass balance (equation (6)) can be eliminated by introducing it into the water mass balance relationship (equation (2)). Making use of the material derivative definition again, the following equation results:

$$
\phi \frac{\mathrm{D}_{\mathrm{s}} \rho_{\mathrm{w}}}{\mathrm{D} t}+\frac{\rho_{\mathrm{w}}}{\rho_{\mathrm{s}}}(1-\phi) \frac{\mathrm{D}_{\mathrm{s}} \rho_{\mathrm{s}}}{\mathrm{D} t}+\rho_{\mathrm{w}} \nabla \frac{\mathrm{d} \mathbf{u}}{\mathrm{d} t}+\nabla\left(\rho_{\mathrm{w}} q_{1}\right)=0
$$

The first two derivatives of this expression can be developed further, taking into account the dependences of the liquid and solid densities on temperature, solid pressure and pore pressure, as follows:

$$
\begin{aligned}
& \rho_{\mathrm{w}}=\rho_{\mathrm{w} 0} \exp \left[\beta_{\mathrm{w}}\left(p_{1}-p_{10}\right)+b_{\mathrm{w}} T\right] \\
& \rho_{\mathrm{s}}=\rho_{\mathrm{s} 0} \exp \left[\beta_{\mathrm{s}}\left(p_{\mathrm{s}}-p_{\mathrm{s} 0}\right)+3 b_{\mathrm{s}}\left(T-T_{\text {ref }}\right)\right]
\end{aligned}
$$

where $\beta_{\mathrm{w}}$ and $\beta_{\mathrm{s}}$ are the water and solid compressibilities respectively, and $b_{\mathrm{w}}$ and $b_{\mathrm{s}}$ are the volumetric and linear thermal expansion coefficients for water and the solid grain respectively. Expanding the first two derivatives of equation (7) results in

$$
\begin{aligned}
{\left[\phi b_{\mathrm{w}}+(1-\phi) 3 b_{\mathrm{s}}\right] \frac{\mathrm{D}_{\mathrm{s}} T}{\mathrm{D} t}+\phi \beta_{\mathrm{w}} \frac{\mathrm{D}_{\mathrm{s}} p_{\mathrm{w}}}{\mathrm{D} t} } \\
\quad+(1-\phi) \beta_{\mathrm{s}} \frac{D_{\mathrm{s}} p_{\mathrm{s}}}{\mathrm{D} t}+\nabla \frac{\mathrm{du}}{\mathrm{d} t}+\frac{\nabla\left(\rho_{\mathrm{w}} q_{1}\right)}{\rho_{\mathrm{w}}}=0
\end{aligned}
$$

Equation (10) contains the THM couplings that explain the variation of pore pressure when a temperature change is applied to the clay. The first term expresses the differential thermal expansion of the solid and liquid phases. The second and third terms are the volume changes of water and solid phase water associated with a pore pressure change; the fourth term is the volume change of the material skeleton (includes contributions from stresses, pore pressures and temperature); and the fifth term is the volume change associated with the flow of water in or out of the element considered. The pore pressure generated will be the result of the interplay of all these terms in each particular case.

The formulation must be completed with various constitutive laws that describe the various phenomena under consideration. They have been presented and discussed elsewhere (e.g. Gens \& Olivella, 2000). The main ones correspond to the flow of heat by conduction, the advective flow of water, and the mechanical constitutive law for mechanical behaviour. 
Heat conduction is governed by Fourier's law:

$$
\mathbf{i}_{\mathrm{c}}=-\lambda \nabla T
$$

where $\lambda$ is the coefficient of thermal conductivity.

Water flow is controlled by Darcy's law:

$$
q_{1}=-K_{1}\left(\nabla p_{1}-\rho_{\mathrm{w}} g\right)=-\frac{k}{\mu_{l}}\left(\nabla p_{1}-\rho_{\mathrm{w}} g\right)
$$

where $K_{1}$ is the liquid permeability and $k$ is the intrinsic permeability. Liquid permeability depends on temperature through the variation of water viscosity, and intrinsic permeability depends on porosity. In non-isothermal problems it is more convenient to characterise the hydraulic conductivity of a material using the concept of intrinsic permeability.

\section{Composite mechanical constitutive law}

A special mechanical constitutive law is adopted for the description of the stress-strain behaviour of the stiff sedimentary clay. It has been presented in Vaunat \& Gens (2003), but a brief description is given here for completeness. It considers the material as a composite, accounting separately for the clay matrix and the bonding (Fig. 3). For simplicity, the equations are expressed here in triaxial space only.

When a load is externally applied to the medium, part of the stresses will be carried by the bonds and part by the matrix. The two materials will then experience different local values of stresses and strains. These values are constrained by the condition that local strains must be compatible with externally applied deformations, by the stress-strain relationships of the matrix and the bonds, and by the fact that local stresses must be in equilibrium with the external load. The model must therefore include a constitutive model for the matrix, a constitutive model for the bonds, and a stress-partitioning criterion to specify the way in which the applied stresses are shared.

Because of the characteristics of the test analysed, matrix strength does not play a significant role, and matrix behaviour is assumed to be elastic. Non-linearity arises from the behaviour of the bonds, defined by means of a damage model that provides a relationship between bond stresses and bond strains. More specifically, the damage model established by Carol et al. (2001) has been selected, in which a logarithmic damage measure is proposed, as follows:

$$
L=\ln \left(\frac{1}{1-D}\right)
$$

Equations defining this law are

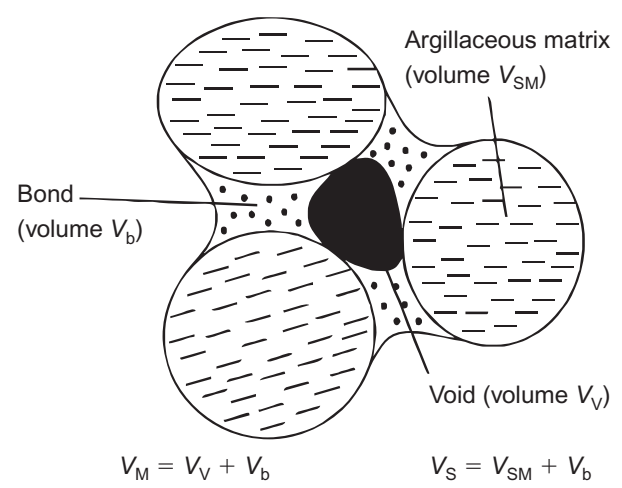

Fig. 3. Conceptual scheme underlying the constitutive law. Material is composed of matrix and bonding

$$
\begin{aligned}
& p_{\mathrm{b}}=(1-D) K_{\mathrm{b} 0} \varepsilon_{\mathrm{v} b}=\mathrm{e}^{-L} K_{\mathrm{b} 0} \varepsilon_{\mathrm{vb}} \\
& q_{\mathrm{b}}=(1-D) G_{\mathrm{b} 0} \varepsilon_{\mathrm{qb}}=\mathrm{e}^{-L} G_{\mathrm{b} 0} \varepsilon_{\mathrm{qb}}
\end{aligned}
$$

where $p_{\mathrm{b}}$ and $q_{\mathrm{b}}$ are the mean and deviatoric bond stress, and $\varepsilon_{\mathrm{vb}}$ and $\varepsilon_{\mathrm{qb}}$ are the volumetric and shear strain (triaxial space).

$D$ is a measure of damage or fissuring of the material, and is equal to the ratio of bond fissures over the whole area of bonds. Fissures are assumed to have null stiffness, and bond material between the fissures is considered as linear elastic, with bulk and shear moduli $K_{\mathrm{b} 0}$ and $G_{\mathrm{b} 0}$. When $D=$ 0 the material is intact, and bond stiffness is determined by $K_{\mathrm{b} 0}$ and $G_{\mathrm{b} 0}$. As $D$ increases, fissures develop and material stiffness reduces progressively. When $D=1$, no more resisting area exists inside the bonding, and bond stiffness is equal to 0 . In this modelling framework, bond response is totally determined if $K_{\mathrm{b} 0}, G_{\mathrm{b} 0}$ and the evolution of $D$ with load are known. According to Carol et al.'s (2001) proposal, change of $D$ is linked to the energy increment input to the bonds $\mathrm{d} u_{\mathrm{b}}$ (equal to $\left(p_{\mathrm{b}}-p_{\mathrm{b} 0}\right) \mathrm{d} \varepsilon_{\mathrm{vb}}+\left(q_{\mathrm{b}}-q_{\mathrm{b} 0}\right) \mathrm{d} \varepsilon_{\mathrm{qb}}$ in triaxial conditions). The following relationship has been used:

$$
r(L)=r_{0} \mathrm{e}^{r_{1} L}=u_{\mathrm{b}}
$$

The current bond damage locus is defined in the stressstrain space as a threshold of equal energy $r$, corresponding to the maximum energy input to the bond during its history. This condition draws an ellipse in $p_{\mathrm{b}}-q_{\mathrm{b}}$ space. For a stress state moving inside the ellipse, no further damage develops. When the ellipse is reached by the current stress state, damage occurs.

Any load applied to an element of cemented material after the time of bond deposition will distribute itself between the soil matrix and the bonding according to a ratio that depends on the geometric arrangement of both components. Cordebois \& Sidoroff (1982) proposed using the energy equivalence principle that establishes the equality between the energy of the composite material and the sum of energies for all components. In this case, this principle leads to the expressions

$$
\begin{aligned}
& p=p_{\mathrm{M}}\left(1+\chi_{\mathrm{v}}\right)+\chi_{\mathrm{v}}\left(p_{\mathrm{b}}-p_{\mathrm{b} 0}\right) \\
& q=q_{\mathrm{M}}\left(1+\chi_{\mathrm{q}}\right)+\chi_{\mathrm{q}}\left(q_{\mathrm{b}}-q_{\mathrm{b} 0}\right)
\end{aligned}
$$

where $p_{\mathrm{M}}$ and $q_{\mathrm{M}}$ are the clay matrix stresses. $\chi_{\mathrm{v}}$ and $\chi_{\mathrm{q}}$ define the part of load $(p, q)$ carried respectively by bonds and matrix. With the assumption that the strains prevailing in the unfissured part of the bonds are equal to $\sqrt{1-D}$ times the bond strains $\left(\varepsilon_{\mathrm{vb}}, \varepsilon_{\mathrm{qb}}\right), \chi_{\mathrm{v}}$ and $\chi_{\mathrm{q}}$ can be rewritten as

$$
\chi_{\mathrm{v}}=\chi_{\mathrm{q}}=\chi=\sqrt{1-D} \chi_{0}
$$

where $\chi_{0}$ is a coefficient related to initial bonding intensity.

According to equation (19), $\chi_{\mathrm{v}}$ and $\chi_{\mathrm{q}}$ evolve from $\chi_{0}$ to 0 during the process of bond damage. This mechanism is accompanied by a destructuration of the material and a progressive transfer of load from bonds to clay matrix. The damage parameter of the bonding component provides a useful variable for relating changes of permeability to increasing degradation of the material. In this case this is achieved by assuming an increase of porosity with damage in accordance with the expression

$$
\phi^{\prime}=\phi+c_{\mathrm{b}} \sqrt{D}
$$

\section{DESCRIPTION OF THE IN SITU TEST}

The in situ heating test (HE-D) is located in the shaly facies of Opalinus clay, which contains a higher proportion 
of clay minerals. To perform the experiment, a niche was excavated from the main laboratory tunnel, from which a $30 \mathrm{~cm}$ diameter borehole (D0) has been drilled horizontally with a total length of $14 \mathrm{~m}$. In the section close to the end of the borehole, two heaters have been installed. The heaters are $2 \mathrm{~m}$ long, and were pressurised to $1 \mathrm{MPa}$ to ensure a good contact with the clay. The separation between heaters is $0.8 \mathrm{~m}$. In addition, various auxiliary boreholes have been constructed to install a variety of instruments for monitoring the test. Fig. 4 shows a top view of the test area. A horizontal test layout was selected in order to have a largely uniform lithology.

Temperatures were measured along two boreholes (D1 and D2) drilled from the niche HE-D. However, perhaps the most relevant observations were those combining measurements of temperatures and pore pressures at the same point in order to relate the two variables directly. This was achieved in borehole D3 (drilled parallel to the heater borehole) and in a series of small-diameter boreholes (D7 to D17) drilled from the MI niche. The pore pressure measurements of sensors located below the main borehole were quite successful, but the pore pressure probes located above the main borehole exhibited a rather slow response, attributed to difficulties encountered in de-airing the sensor area. Finally, sliding micrometer tubing was installed in boreholes D4 and D5 to measure incremental deformations at $1 \mathrm{~m}$ intervals. Special care was taken to ensure accuracy in the direction and length of the instrumentation boreholes to guarantee the correct location of the sensors. All instruments were in place before the drilling of the main borehole containing the heaters. In this way hydro-mechanical effects during excavation could also be recorded.

Approximately one month after installation and pressurisation, the heaters were switched on with a total power of

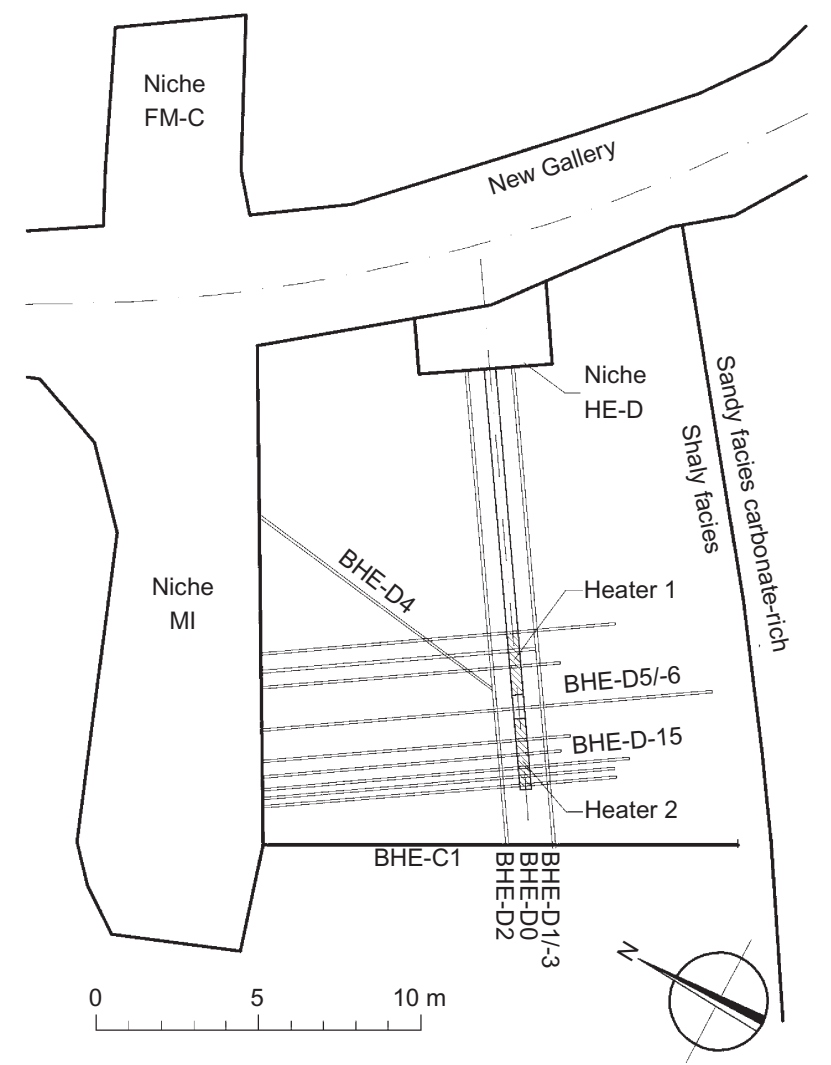

Fig. 4. Schematic layout of in situ test HE-D. Locations of observation boreholes drilled from niches HE-D and MI are shown
$650 \mathrm{~W}$ ( $325 \mathrm{~W}$ per heater). The heaters were then left under constant power for 90 days. Afterwards the power was increased threefold, to $1950 \mathrm{~W}$ ( $975 \mathrm{~W}$ per heater), and maintained at that level for a further 248 days. At the end of this second heating stage, the heaters were switched off and the clay was allowed to cool down. Temperatures, pore pressures and deformations were measured throughout. In Fig. 5 the position of the main temperature and pore pressure sensors with respect to heater axis are indicated, together with the main orientation of the bedding planes. Heater 2 became depressurised because of a leak 109 days after the start of the heating. This event did not noticeably affect the development of the test.

\section{NUMERICAL SIMULATION AND INTERPRETATION OF} TEST RESULTS

Features of analysis and clay properties

Interpretation of the patterns of behaviour exhibited by the test observations will be aided by the results of a finite

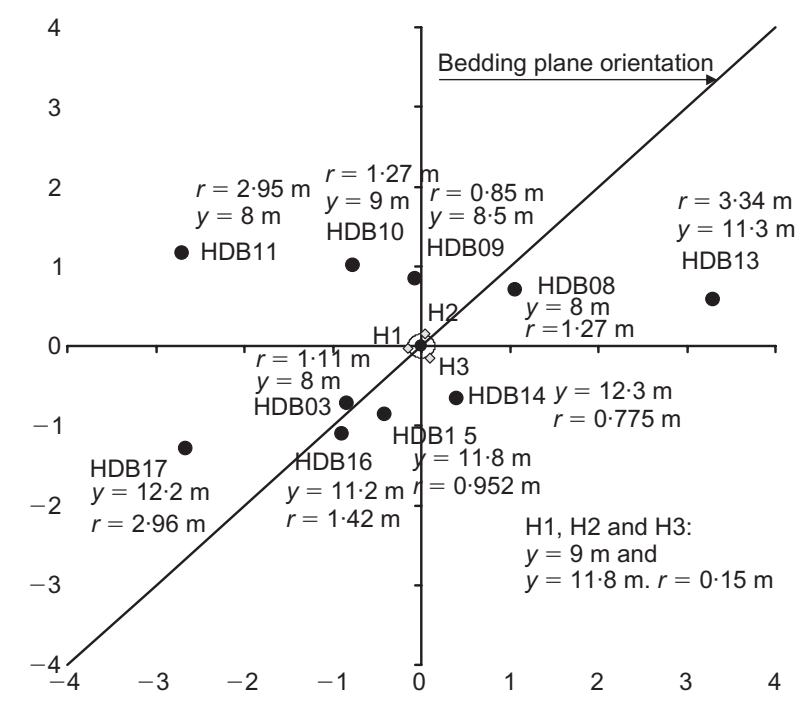

Fig. 5. Location of main observation points in HE-D in situ test. Coordinate $r$ is distance to axis of main borehole Do containing the heaters. Coordinate $y$ represents distance to HE-D niche. For reference, mid-point between the two heaters lies at coordinate $y=10.4 \mathrm{~m}$; centres of two heaters lie at values of $y$ of $9 \mathrm{~m}$ and $11.8 \mathrm{~m}$ respectively

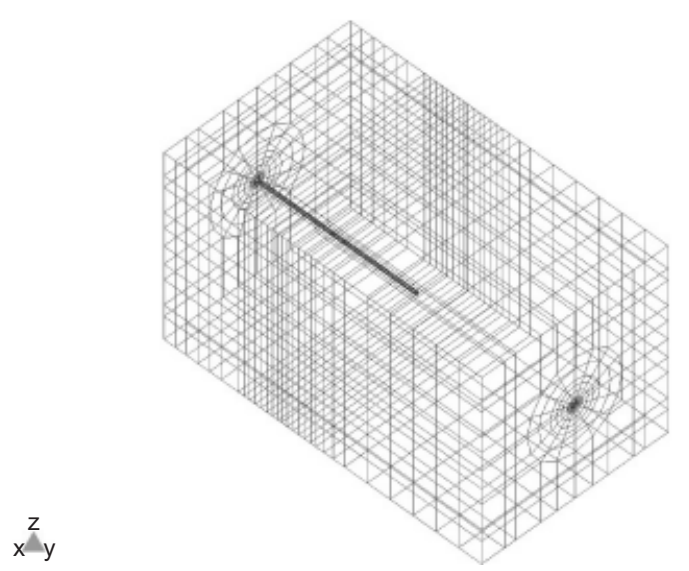

Fig. 6. Finite element mesh three-dimensional analysis. Dimensions are $16 \mathrm{~m} \times 16 \mathrm{~m} \times 28 \mathrm{~m}$. Computation domain centred on axis of main borehole 
element simulation of the experiment. A three-dimensional coupled THM analysis has been performed in order to incorporate the anisotropic properties of the clay and the anisotropy of the in situ stress state. The domain modelled and the finite element mesh used are depicted in Fig. 6. The dimensions are $16 \mathrm{~m} \times 16 \mathrm{~m} \times 28 \mathrm{~m}$ and the computation domain is centred on the axis of the main borehole. The distance to the boundary is $8 \mathrm{~m}$, which corresponds to the distance from the borehole axis to the niche MI. Different boundary conditions are selected for the two lateral surfaces. A constant stress boundary is assumed on the surface that corresponds to the cavity MI (thereby allowing some lateral displacement), whereas a condition of constrained lateral displacements is adopted for the opposite lateral boundary.

The initial water pressure was set to the field-measured value of $0.9 \mathrm{MPa}$, lower than the value typical of the massif because of the influence of the various tunnels and niches present in the area. Values of $7 \mathrm{MPa}, 5 \mathrm{MPa}$ and $3 \mathrm{MPa}$ as major, intermediate and minor initial principal stresses were assigned to the domain, consistent with the information in Table 3 . The pore pressures on the borehole boundary are set to atmospheric. Initial temperature is $15^{\circ} \mathrm{C}$. The various stages of the experiment were mimicked by the various phases of the numerical analyses. They are listed in Table 4. The start of heating is adopted as the origin of the timescale.
Because the aim of the analysis was interpretation and not prediction, some of the clay parameters that were deemed especially important were determined from field observations. For instance, a proper interpretation of the thermohydraulic coupling requires a good representation of the thermal field throughout the domain. To achieve this, it is necessary to know, as precisely as possible, the value of the thermal conductivity of the clay. A three-dimensional back-

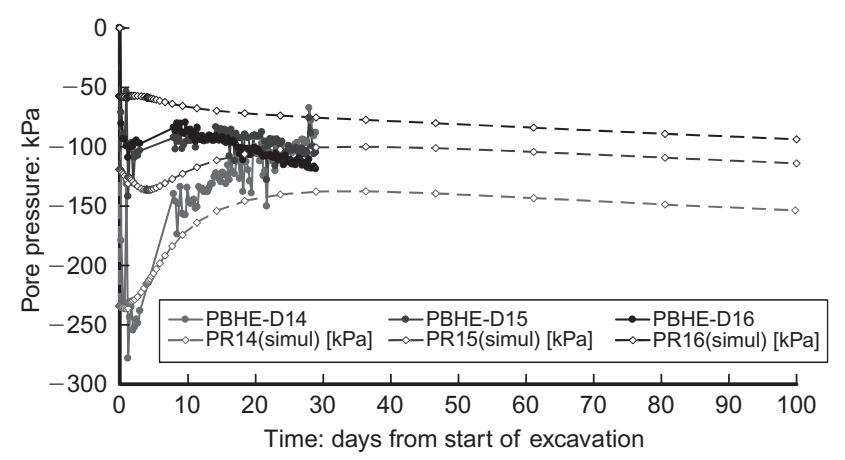

Fig. 7. Evolution of pore pressures during excavation of main boreholes: observed values and computed results using backcalculated parameters

Table 4. Phases of the analyses

\begin{tabular}{l|c|c|c|l}
\hline Phase & Start: day & End: day & Duration: days & Activity \\
\hline 1 & -29 & $-27 \cdot 75$ & 1.25 & Excavation \\
2 & $-27 \cdot 75$ & $-23 \cdot 75$ & 4 & Placement of heaters \\
3 & $-23 \cdot 75$ & 0 & $23 \cdot 75$ & Heaters pressurised (1 MPa) \\
4 & 0 & 91 & 248 & First heating phase (325 W/heater) \\
5 & 91 & 339 & 179 & Second heating phase (975 W/heater) \\
6 & 339 & 518 & Cooling phase \\
\hline
\end{tabular}

Note: On day 109 the heater pressure is set to zero to simulate an accidental pressure loss of the heaters that actually occurred during the in situ experiment.

Table 5. Clay properties adopted in the 3D THM analysis

\begin{tabular}{|c|c|c|c|c|}
\hline & Parameter & Orientation* & Value & \\
\hline Mechanical properties & Young's modulus, $E: \mathrm{MPa}$ & $\begin{array}{l}\text { Parallel } \\
\text { Perpendicular }\end{array}$ & $\begin{array}{l}9300 \\
5800\end{array}$ & $\begin{array}{l}\text { Back-analysis of borehole } \\
\text { excavation. Anisotropic } \\
\text { stiffness ratio from Bock } \\
(2001) \\
\text { Reference value }\end{array}$ \\
\hline $\mathrm{H}$ properties & Biot coefficient, $b$ & - & $\begin{array}{c}5 \cdot 10-\mathrm{m}^{2} \\
0 \cdot 6\end{array}$ & $\begin{array}{l}\text { Back-analysis from } \\
\text { borehole excavation } \\
\text { Reference value }\end{array}$ \\
\hline TM properties & $\begin{array}{l}\text { Linear thermal expansion of solid, } \\
\alpha_{\mathrm{T}}: \mathrm{K}^{-1} \\
\text { Linear thermal expansion of the solid } \\
\text { grain, } b_{\mathrm{s}}: \mathrm{K}^{-1}\end{array}$ & $\begin{array}{l}\text { Parallel } \\
\text { Perpendicular } \\
-\end{array}$ & $\begin{array}{l}1.7 \times 10^{-5} \\
1 \cdot 1 \times 10^{-5} \\
1.4 \times 10^{-5}\end{array}$ & $\begin{array}{l}\text { Value and anisotropic } \\
\text { ratio from Auvray (2004) } \\
\text { Auvray (2004) }\end{array}$ \\
\hline $\mathrm{T}$ properties & $\begin{array}{l}\text { Thermal conductivity, } \lambda: \mathrm{W} /(\mathrm{m} \mathrm{K}) \\
\text { Specific heat capacity of the solid, } \\
c_{\mathrm{s}}: \mathrm{J} /(\mathrm{kg} \mathrm{K})\end{array}$ & $\begin{array}{l}\text { Parallel } \\
\text { Perpendicular } \\
-\end{array}$ & $\begin{array}{l}2 \cdot 8 \\
1 \cdot 6 \\
840\end{array}$ & $\begin{array}{l}\text { Anisotropic back-analysis } \\
\text { of thermal field } \\
\text { Auvray (2004) }\end{array}$ \\
\hline Petrophysical properties & $\begin{array}{l}\text { Solid compressibility, } \beta_{\mathrm{s}}: \mathrm{MPa}^{-1} \\
\text { Specific weight, } \rho_{\mathrm{s}}: \mathrm{kg} / \mathrm{m}^{3} \\
\text { Porosity, } \phi\end{array}$ & $\begin{array}{l}- \\
- \\
-\end{array}$ & $\begin{array}{c}2.5 \times 10^{-5} \\
2.7 \\
0 \cdot 137\end{array}$ & $\begin{array}{l}\text { From mineral } \\
\text { composition } \\
\text { Reference value } \\
\text { Martin \& Lanyon (2003) }\end{array}$ \\
\hline
\end{tabular}

\footnotetext{
* Orientation to bedding.
} 
analysis exercise has been performed to find the value of thermal conductivity that achieves the closest agreement with measured temperatures, according to the least-squares criterion. This has required the performance of several 3D purely thermal analyses. The following values of thermal conductivity were obtained: $2.8 \mathrm{~W} /(\mathrm{mK})$ in the direction parallel to the bedding, and $1.6 \mathrm{~W} /(\mathrm{mK})$ in the direction perpendicular to the bedding.

The stiffness (Young's modulus) and permeability of the clay have been obtained from a back-calculation of the evolution of pore pressures measured in the clay when the main borehole was excavated. Because of the large number of coupled HM analyses to be performed, an axisymmetric model was used for this purpose. Therefore only averaged isotropic parameters could be determined in this way. The parameter values obtained were $E=7500 \mathrm{MPa}$ and intrinsic permeability $k=5 \times 10^{-20} \mathrm{~m}^{2}$ (approximately $5 \times 10^{-13} \mathrm{~m} / \mathrm{s}$ for water at $15^{\circ} \mathrm{C}$ temperature). The agreement reached can be seen in Fig. 7. The pore pressure peak observed is quite sensitive to the value of $E$, whereas the rate of decay depends mainly on permeability. Thus the two parameters can be identified in a relatively independent way.

A list of the basic clay parameters used in the analyses is given in Table 5, with an indication of the source used to derive some of the values. It can be observed that many of the properties exhibit anisotropy. No clear evidence of anisotropy of permeability has been obtained (Bock, 2001; Croisé et al., 2004; Coll, 2005), so the single back-calculated value has been used. In contrast, an anisotropic Young's modulus has been adopted, consistent with the average back-calculated value but keeping the measured

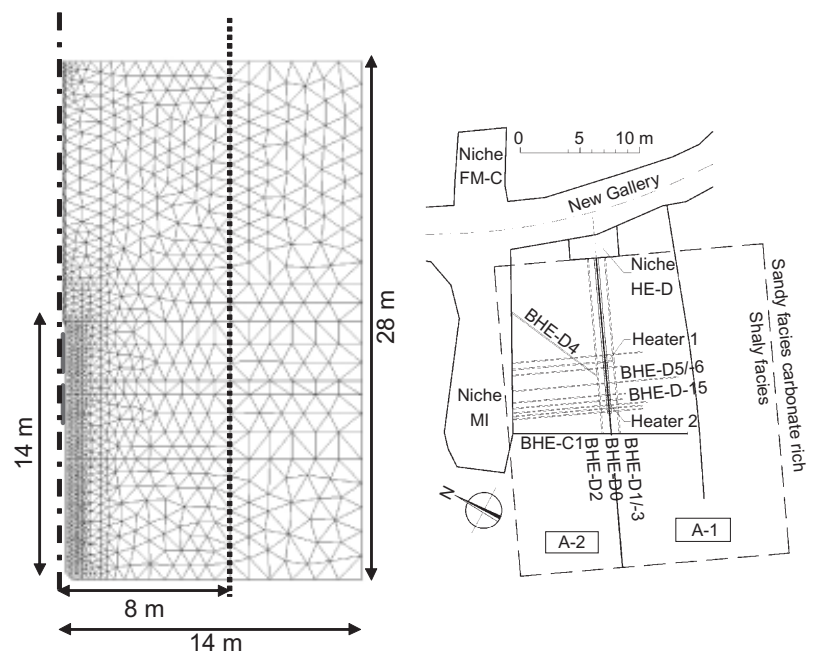

Fig. 8. Domain modelled and finite element mesh used in axisymmetric analyses $\mathrm{A} 1$ and $\mathrm{A} 2$

ratio of stiffness normal and parallel to the bedding direction.

Model parameters for the mechanical constitutive model (Table 6) have been based mainly on the experimental database of the material. Some mineral physical data have also been used to characterise bond stiffness. Finally, the combination of the Young's moduli of bonding and matrix has been selected in such a way that the global values of the Young's moduli derived from the observations during the

Table 6. Parameters of the composite mechanical constitutive model used in the 3D THM analysis

\begin{tabular}{l|l|c}
\hline Parameter & Orientation* & Value \\
\hline Bonding Young's modulus, $E_{\mathrm{b} 0}: \mathrm{MPa}$ & Parallel & 18150 \\
& Perpendicular & 11315 \\
Matrix Young's modulus, $E_{\mathrm{m}}: \mathrm{MPa}$ & Parallel & 3720 \\
& Perpendicular & 2320 \\
Bonding Poisson's ratio, $v_{\mathrm{b}}$ & - & $0 \cdot 295$ \\
Matrix Poisson's ratio, $v_{\mathrm{m}}$ & - & $0 \cdot 295$ \\
Structuration parameter, $\chi$ & - & $1 \cdot 2$ \\
Bonding concentration, $c_{\mathrm{b}}$ & - & $0 \cdot 3$ \\
Damage threshold, $r_{0}: \mathrm{MPa} \mathrm{m} / \mathrm{m}$ & - & $1 \times 10^{-3}$ \\
Damage evolution, $r_{1}$ & - & $1 \cdot 8$ \\
\hline
\end{tabular}

* Orientation to bedding.

Table 7. Clay properties used in the axisymmetric analyses; the values used in the 3D simulation are presented for comparison

\begin{tabular}{|c|c|c|c|}
\hline & Parameter & Axisymmetric analysis & $3 \mathrm{~d}$ analysis \\
\hline Mechanical properties & $\begin{array}{l}\text { Young's modulus, } E \text { : Mpa } \\
\text { Bonding Young's modulus, } E_{\mathrm{b} 0}: \mathrm{Mpa} \\
\text { Matrix Young's modulus, } E_{\mathrm{m}}: \mathrm{Mpa}\end{array}$ & $\begin{array}{l}7500 \\
14640 \mathrm{Mpa} \\
3000\end{array}$ & $\begin{array}{l}9300^{/ /} \\
5800^{\perp} \\
18150^{/ /} \\
11315^{\perp} \\
3720^{/ /} \\
2320^{\perp}\end{array}$ \\
\hline TM properties & $\begin{array}{l}\text { Linear thermal expansion of solid, } \\
\alpha_{\mathrm{T}}: \mathrm{K}^{-1}\end{array}$ & $1.4 \times 10^{-5}$ & $\begin{array}{l}1.72 \times 10^{-5 / /} \\
1.1 \times 10^{-5 \perp}\end{array}$ \\
\hline $\mathrm{T}$ properties & Thermal conductivity, $\lambda: \mathrm{W} /(\mathrm{m} \mathrm{K})$ & $2 \cdot 2$ & $\begin{array}{l}2 \cdot 8^{/ /} \\
1 \cdot 6^{\perp}\end{array}$ \\
\hline
\end{tabular}

// Parallel to bedding.

$\perp$ Perpendicular to bedding. 
excavation of the borehole are recovered. Nevertheless, there is considerable uncertainty in the values of some of the parameters because of lack of sufficient laboratory or field evidence. The parameter $r_{0}$, which controls the damage threshold, and the parameter $r_{1}$, which defines the damage evolution, are examples of this. The values adopted have been derived by analogy from tests performed in another stiff sedimentary clay: the Callovo-Oxfordian clay from the Meuse/Haute Marne laboratory.

For reference, two axisymmetric analyses have been performed and the results compared with those of the 3D simulation. The domain modelled and the finite element meshes adopted are depicted in Fig. 8. In the analysis (A1) the domain has a length of $28 \mathrm{~m}$ and a width of $14 \mathrm{~m}$. A second analysis (A2) has been run with a width of $8 \mathrm{~m}$ only, to examine the possible effect of the presence of Niche MI $8 \mathrm{~m}$ away from the main borehole. Naturally the symmetry axis coincides with the axis of the main borehole D0 containing the pressurised heaters. The in situ stress has been represented by a normal stress of $4.2 \mathrm{MPa}$ applied to the boundary. This value is an approximate average of the anisotropic stress state values. Material parameters of the axisymmetric analyses are the same as in the $3 \mathrm{D}$ computation, except for the properties where anisotropy has been assumed (Table 7). A preliminary axisymmetric analysis of this test using a simplified model and different material parameters has been reported in Gens et al. (2006).

\section{Thermal results}

The observed evolution of temperatures at the interface between heaters and clay is shown in Fig. 9 together with the computed results from the $3 \mathrm{D}$ analysis. The two heating stages and the cooling phase can be clearly identified. Maximum temperatures reach values just above $100^{\circ} \mathrm{C}$ at the end

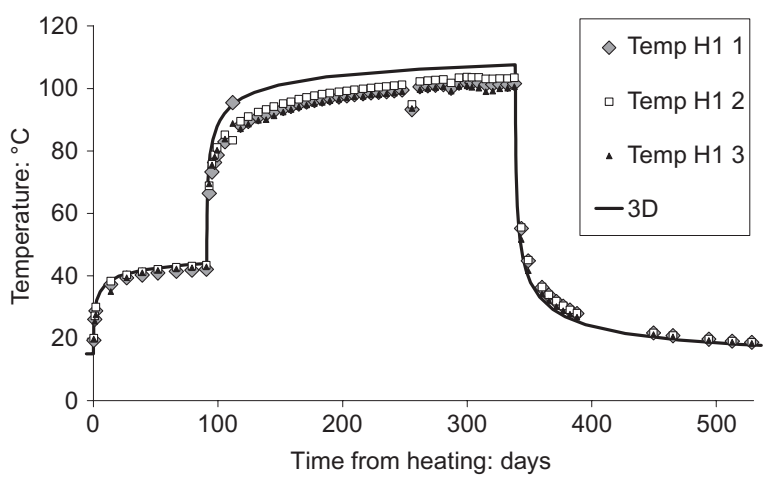

(a)

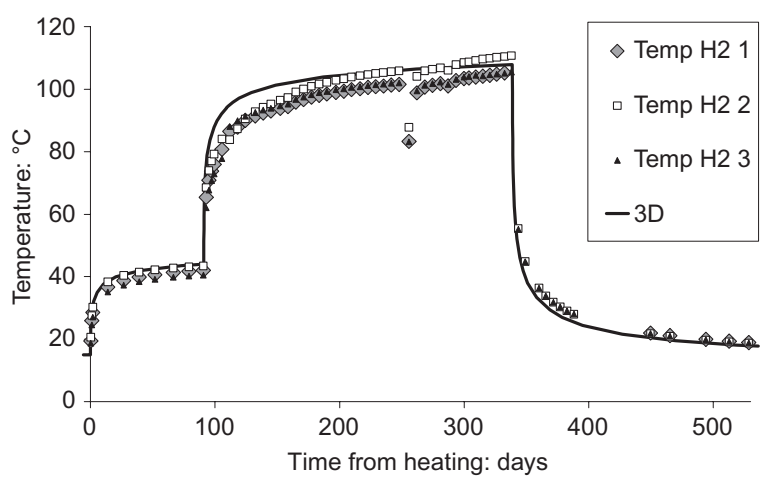

(b)

Fig. 9. Evolution of temperatures on heater/clay interface surface throughout the test: (a) Heater H1; (b) Heater H2

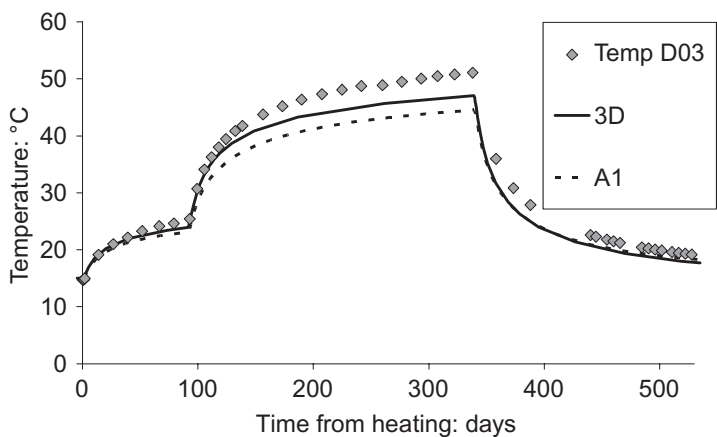

(a)

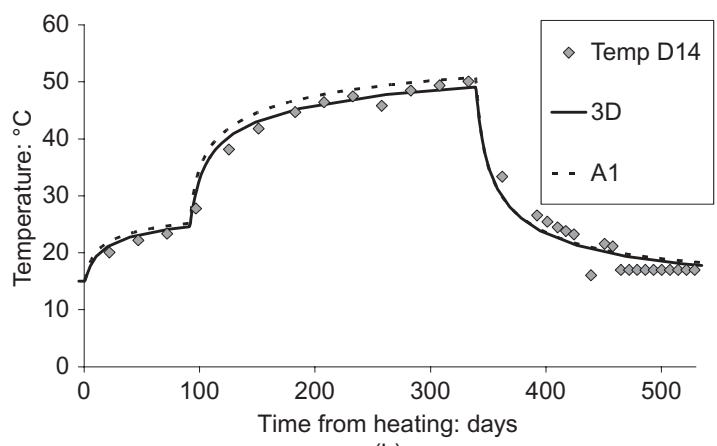

(b)

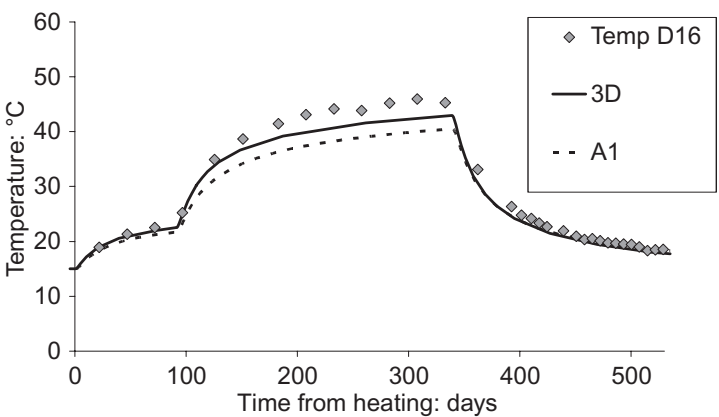

(c)

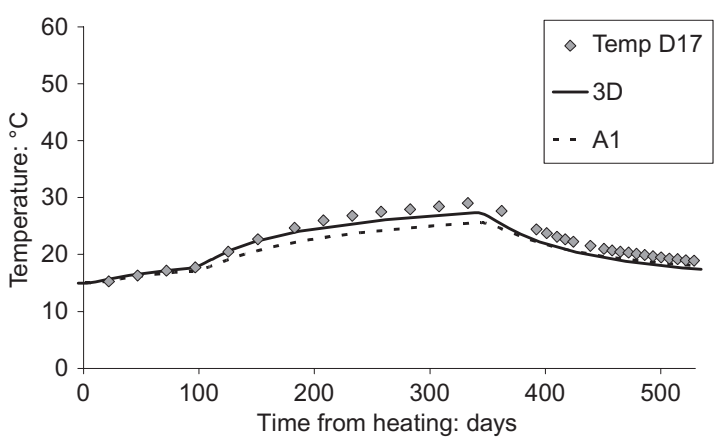

(d)

Fig. 10. Evolution of temperatures at various points in the clay: observed and computed results

of the second heating stage. There were three sensors in each heater, set at different orientations with respect to bedding. However, anisotropic effects are hardly noticeable; very similar temperatures are recorded at all three points. The 3D analysis captures the temperature variation well; of course, thermal conductivity has been back-calculated, and conduction is the dominant form of heat transport. In any case, the whole evolution of temperatures is correctly reproduced. In this instance, the axisymmetric results coincide exactly with the $3 \mathrm{D}$ computations and are not plotted.

Anisotropic effects are more noticeable in the temperatures measured in the clay mass (Fig. 10). Take, for instance, 

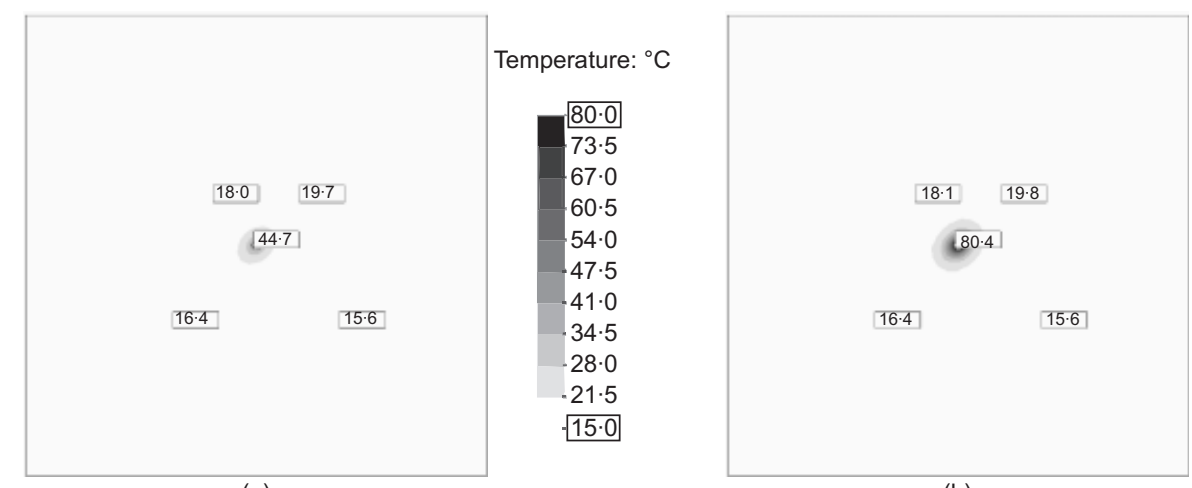

(a)

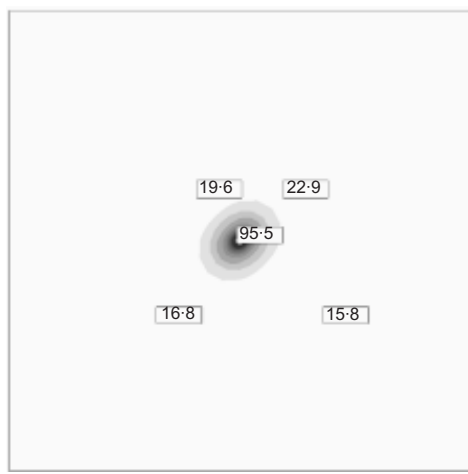

Temperature: ${ }^{\circ} \mathrm{C}$

(c)
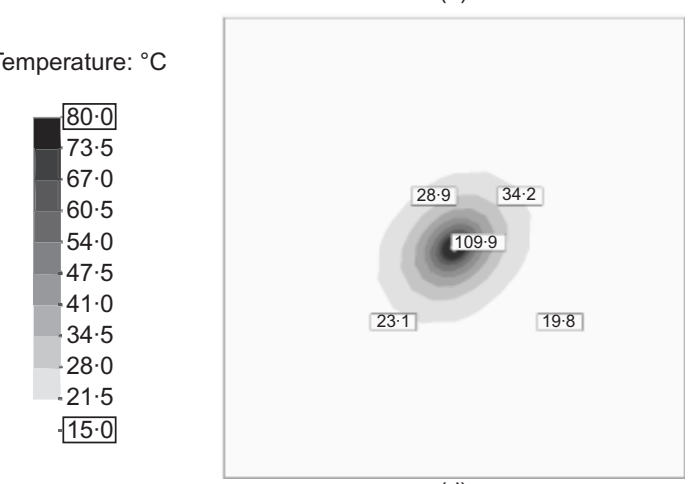

(d)

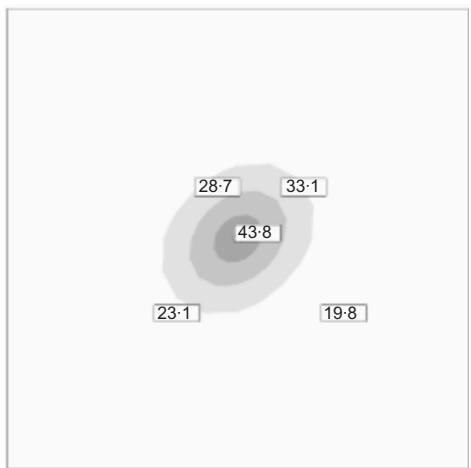

Temperature: ${ }^{\circ} \mathrm{C}$

(e)
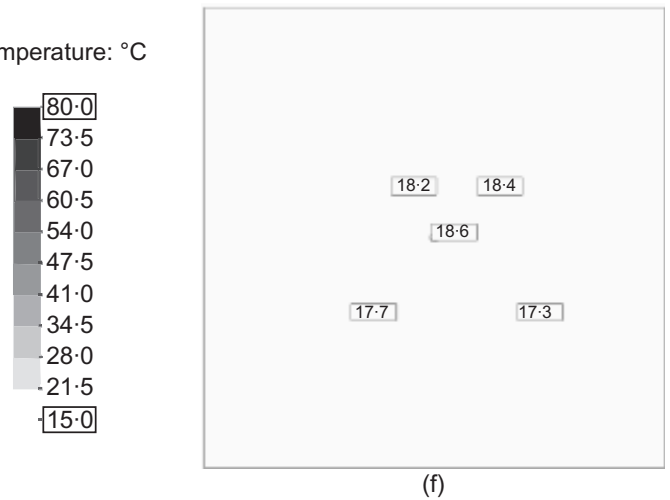

Fig. 11. Computed contours of equal temperature $\left({ }^{\circ} \mathrm{C}\right)$ in a cross-section across Heater 2 for: (a) 90 days; (b) 93 days; (c) 110 days; (d) 338 days; (e) 346 days; (f) 501 days

points D03 and D14: the first is oriented parallel to the bedding with respect to the main borehole, and the second is perpendicular to the bedding. They reach a similar temperature, about $50^{\circ} \mathrm{C}$, although they are located at different distances from the heater axis. It can be seen that the results of the 3D analysis (which include thermal conductivity anisotropy) are closer to the observed temperatures, although the differences from the axisymmetric computations are not large. Only axisymmetric analysis A1 is plotted, because the results of analysis $\mathrm{A} 2$ are the same.

More information from the analyses is given in Fig. 11 in terms of contours in a section across Heater 2 at various relevant stages. The following times have been selected for plotting: 90 days (end of the first heating stage); 93 days (just after the start of the second stage of heating); 110 days (time at which maximum pore pressures are achieved); 338 days (at the end of the second stage of heating); 346 days (during the cooling phase); and 501 days (towards the end of cooling phase). The anisotropic temperature distribution is apparent, with higher temperatures being reached in the direction of the bedding planes. Similar information is presented in Fig. 12 in a three-dimensional view.
The distributions of temperatures on the section across Heater 2 are plotted in Fig. 13 for the same times as selected before. The progressive rise of temperature can be readily observed, as well as the subsequent temperature reduction during the cooling period. It is interesting to note that the region with a significant temperature increase appears to be limited to a radius of about $5 \mathrm{~m}$ around the main borehole.

\section{Pore pressures}

As expected, temperature increases triggered a large upsurge of pore pressures. A typical set of observations is presented in Fig. 14, where the temperature and pore pressure recorded in borehole D03 are plotted. It is noticeable that the pore pressure responds immediately to the rise of temperature, and the larger the change of temperature is, the stronger is the response. The maximum pore pressure increase in this case is $2.5 \mathrm{MPa}$, a significant magnitude. It can also be observed that the pore pressure evolution does not exactly match that of temperature: at some time the pore pressure stops rising, even though temperatures increase 


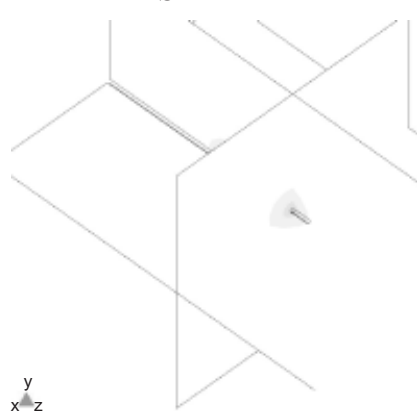

(a)

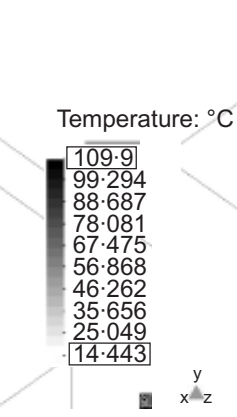

$x_{x \rightarrow 2}^{x}$

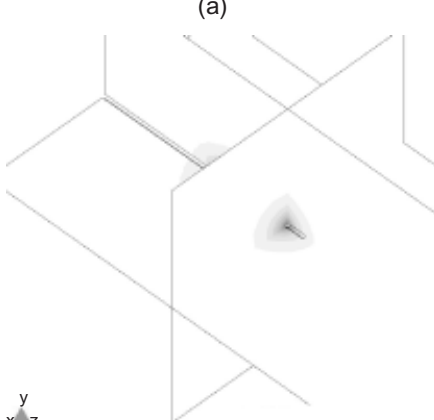

(c)

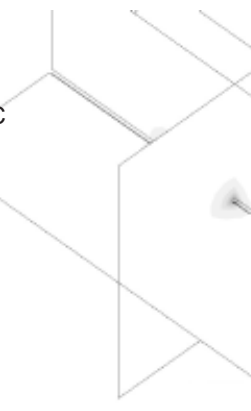

Temperature: ${ }^{\circ} \mathrm{C}$

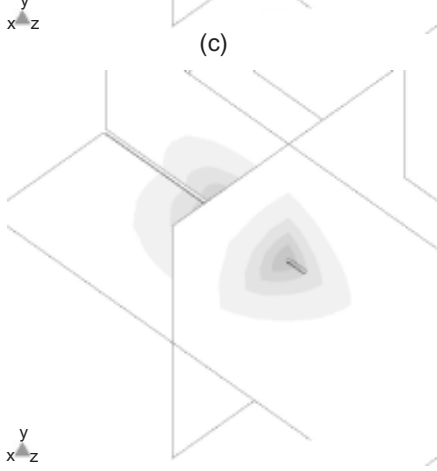

(e)

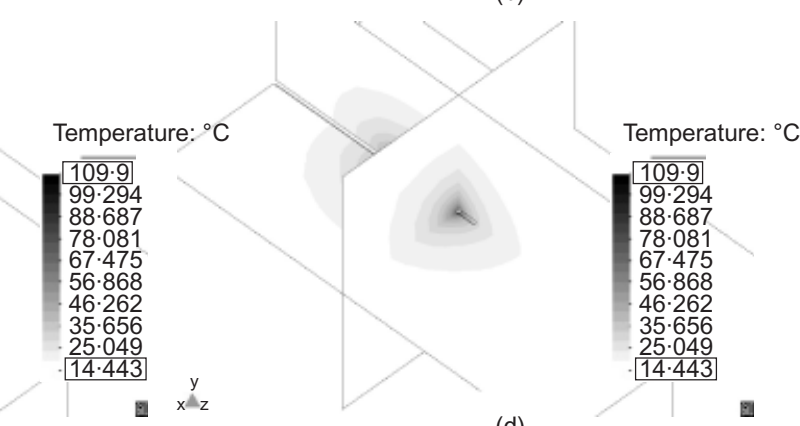

(d)

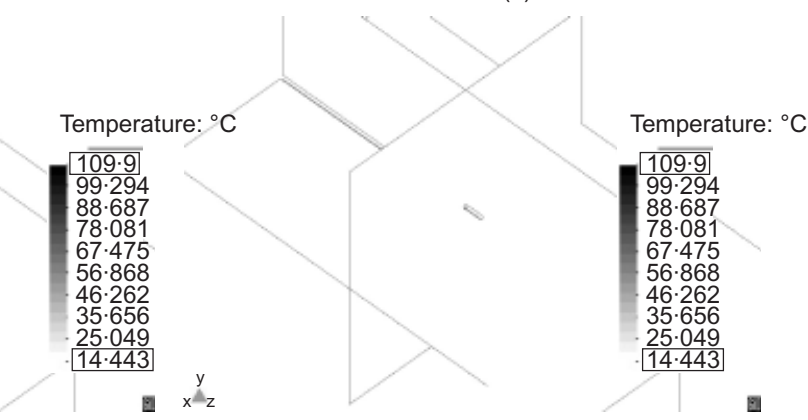

(f)

Fig. 12. Three-dimensional view of computed contours of equal temperature $\left({ }^{\circ} \mathrm{C}\right)$ for: (a) 90 days; (b) 93 days; (c) 110 days; (d) 338 days; (e) 346 days; (f) 501 days

further. Obviously, dissipation by liquid flow overcomes the thermal effect. This phenomenon is especially noticeable in the second stage of heating.

A comparison between the results of the $3 \mathrm{D}$ analysis and observations, in terms of pore pressure increases, for various points of the clay mass is presented in Fig. 15. The results of the two axisymmetric analyses have also been added for reference. It is apparent that the maximum pore pressure increase is reasonably well captured with the formulation and parameters used. The evolution of pore pressure is also reproduced well, with the noticeable exception of borehole D17, located further away from the heaters. The pore pressure rise in the first heating stage seems to be sharper in the computations than in the observations. This could be due to a slow response of the pore pressure sensors; it is significant that in the second stage the observed and computed rates of pore pressure increase appear to be the same.

In Fig. 15, the time at which the maximum pore pressure increase is calculated is indicated for each measurement point. The time becomes larger as the distance to the main borehole increases. This results from the combined effect of the movement of temperature rise outwards and of pore pressure dissipation from the inner zones. This evolution can easily be observed in Fig. 16, where two pore pressure distributions on a section perpendicular to the main borehole and located between the two heaters are plotted for various significant times. It can be seen that the cooling associated with the switching off of the heaters induces a pore pressure reduction, the counterpart of the pore pressure increase during heating. The two distributions plotted correspond to two orthogonal directions, one along the bedding plane and the other normal to the bedding. Some differences between the two sets of distributions can be observed, especially for shorter times. These differences do not arise from hydraulic effects (permeability has been assumed isotropic) but from the differential temperature rise caused by thermal conductivity anisotropy.

Anisotropy of generated pore pressures can also be observed in the contours of equal pore pressure presented in Figs 17 and 18. The displacement of the maximum pore pressure away from the main borehole as time goes on is also readily apparent. In addition, it is interesting to note (Figs 15, 16, 17(f) and 18(f)) that, at the end of the experiment, pore pressures have not yet returned to equilibrium levels. Close to the heater, pore pressures are depressed owing to the reduction brought about by cooling. In contrast, some positive excess pore pressures prevail away from the heater, where temperature changes are more gradual.

\section{Displacements}

The combined effects of temperature changes and pore pressure generation and dissipation cause mechanical effects. 


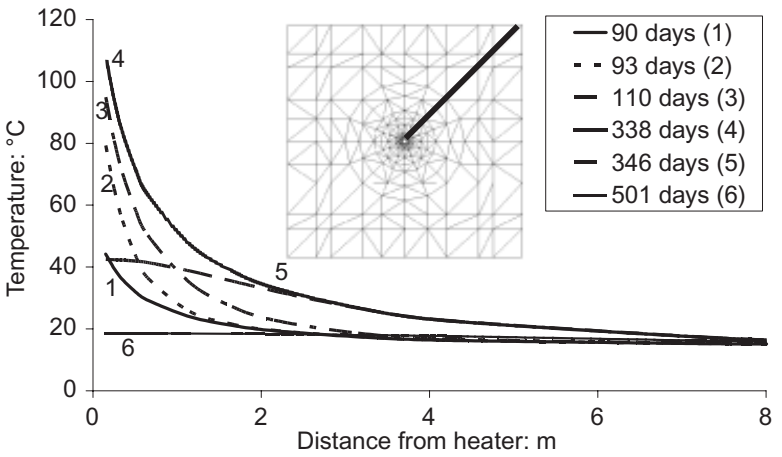

(a)

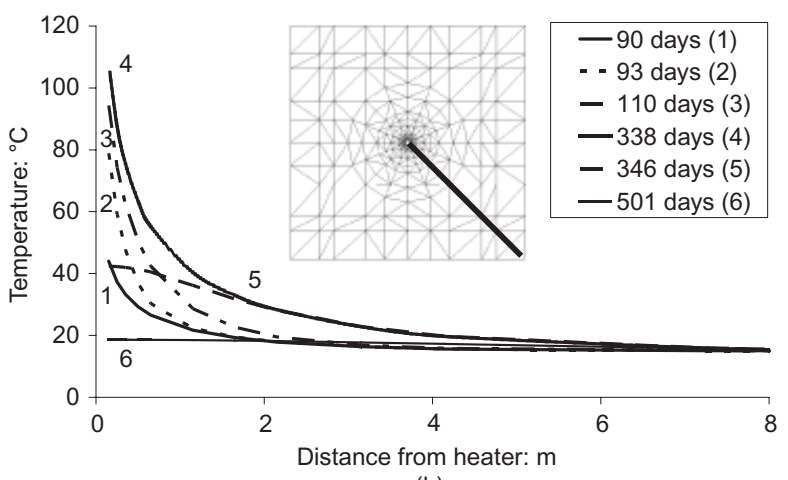

(b)

Fig. 13. Computed temperature distributions at various times on section across Heater 2: (a) bedding plane direction; (b) perpendicular to bedding plane direction

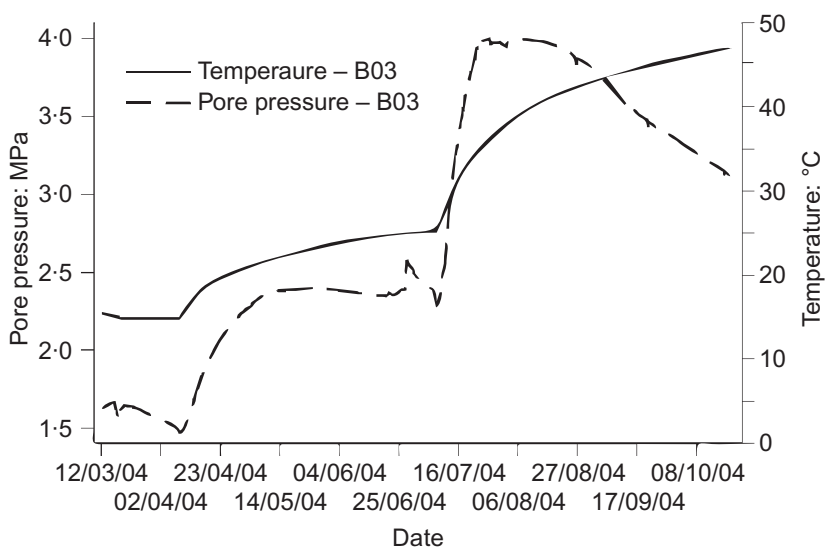

Fig. 14. Evolution of temperature and pore pressure in borehole D3 during in situ test

Those effects were monitored during the performance of the in situ test by measuring relative displacements in boreholes D4 and D5 using a sliding micrometer (Fig. 19). Fig. 20 shows the movements measured along borehole D5 at various times. This borehole was drilled from Niche MI at a direction approximately normal to the main borehole. It can be observed that, in the region around the heaters, extension deformations occur, but they become compressive strains at locations further away from the heater. The dilation of the clay close to the heater, driven by thermal expansion, is partially taken up by the compression of the outer zones.

The evolution of strains of some selected intervals is shown in Figs 21 and 22 (boreholes D4 and D5 respectively) together with the computed results from the 3D analysis. Again, the results from the two axisymmetric computations are added for comparison. A first observation is the very small magnitude of the strains (and hence displacements) measured and computed, consistent with the high stiffness exhibited by the clay. It can be seen that, in borehole intervals close to the heater (e.g. intervals $6-7,7-8$ and $8-$ 9 of borehole D-5), dilatant strains are observed in response to the temperature increase; indeed, the two heating stages can be easily identified. In contrast, in borehole intervals away from the heater (e.g. intervals $11-12$ and 12-13), a compressive strain is measured initially, as a result of the expansion of the inner regions of the test. When the thermal field extends with time, the material expands, and compressive strains become dilatant strains. In spite of some scatter of the observations (a consequence of the small magnitudes being measured), the numerical analyses satisfactorily capture the main patterns of behaviour.

The interplay between compressive and dilatant strains can also be examined by reference to Fig. 23, where the distributions of computed radial displacements at various times are presented. Displacement differences can be observed in the computed distributions when plotted parallel and perpendicular to the bedding direction resulting from the combined effect of the anisotropy considered for stiffness and thermal dilation properties. It can also be seen that radial displacements exhibit a peak. Clay expansion occurs before the maximum of displacements (which are always directed outwards), and the material contracts in the zone after the peak. The transition between the two strain regions migrates slowly outwards. By reference to Fig. 13, it can be seen that the region of dilatant strains coincides with the zone in which temperature increases are significant, and compressive strains prevail where the temperature rise is small or negligible. This phenomenon is also directly illustrated in Fig. 24, where the distributions of computed radial displacements and temperatures for a particular time and direction are plotted together.

\section{Damage zone}

The mechanical constitutive model used in the 3D analysis (and also in the axisymmetric analyses reported so far) incorporates the concept of a bonding subject to damage as a constituent part of the material. The onset and development of damage degrades the elastic parameters in accordance with equations (14) and (15). Although there is significant uncertainty regarding the parameters defining the damage threshold and evolution, it is of interest to investigate the extent to which, according to the model, the damage zone has spread during the in situ test. Fig. 25(a) shows the distributions, at various times, of the unloading elastic modulus (the main parameter affected by the degree of damage) along a horizontal direction in a section perpendicular to Heater 2. The model reproduces the possible damage of the clay due to thermal loading in the initial stages of heating. Afterwards, the damaged zone becomes larger during pore pressure dissipation because of the consequent increase of effective stress. During the cooling period, damage does not develop further.

During the dismantling of the in situ test, a borehole was drilled from the MI niche, perpendicular to the main borehole. The unconfined Young's moduli of a series of samples taken from this borehole at different distances from the heaters were determined by means of measurement of the compression wave velocity. The measured moduli have been added to the plot of Fig. 25(a). The values obtained appear to confirm the existence of a damaged zone close to the heaters but, perhaps, not extending back into the clay as much as shown by the computations at later times. The amount of independent experimental data, however, is not 


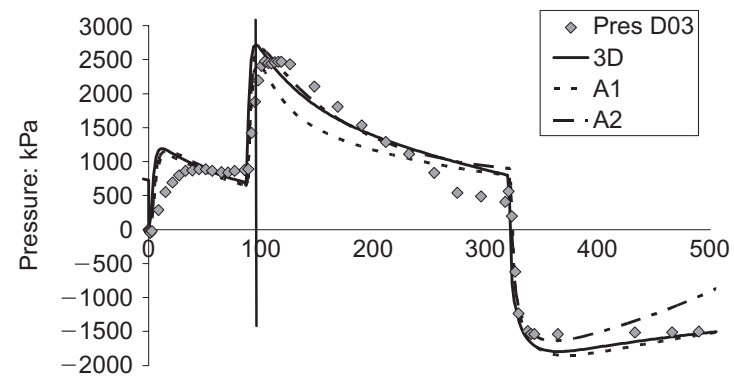

(a)

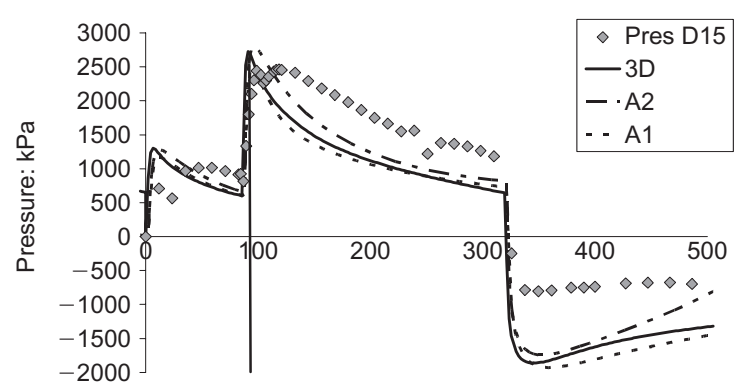

Time from heating: days

(c)

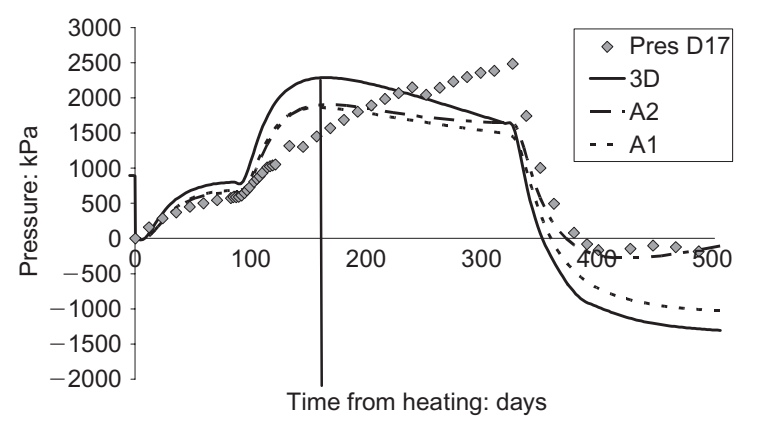

(e)

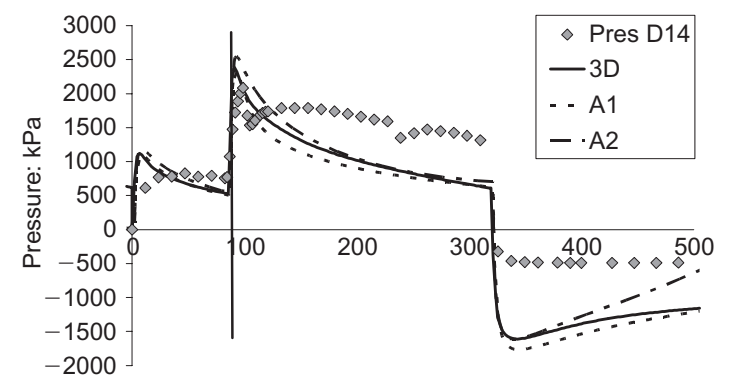

Time from heating: days

(b)

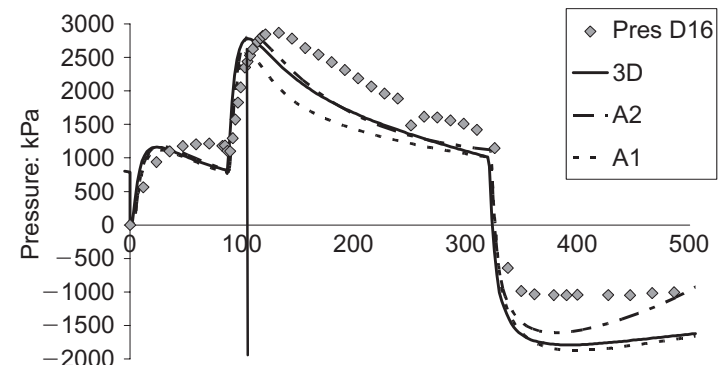

Time from heating: days

(d)

Fig. 15. Evolution of pore pressure increments at various points in the clay: observed and computed results

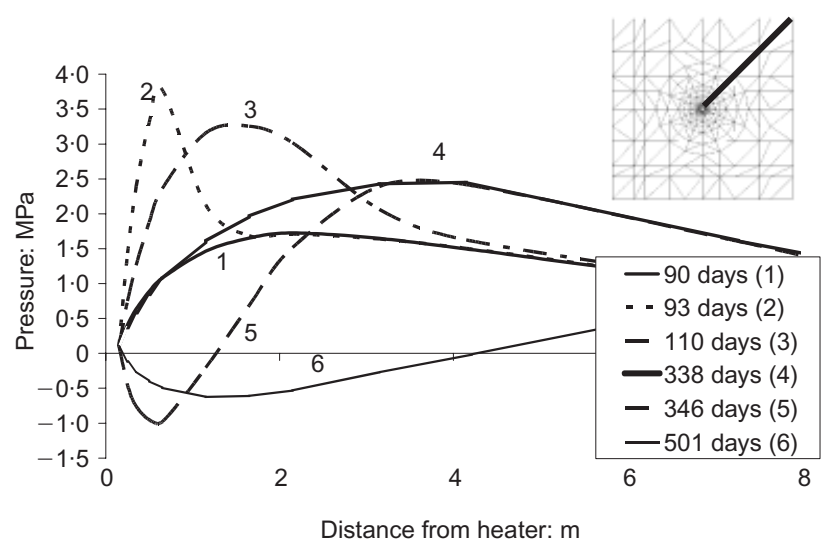

(a)

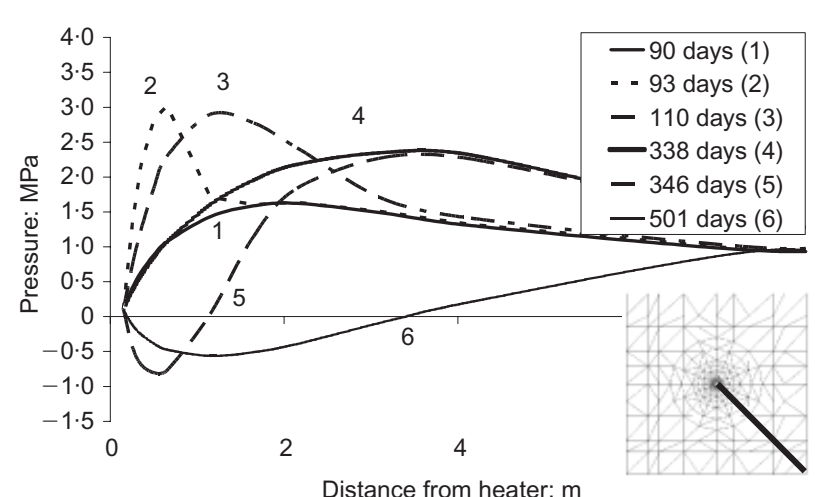

(b)

Fig. 16. Computed pore pressure increment distributions at various times on section across Heater 2: (a) bedding plane direction; (b) perpendicular to bedding plane direction

sufficient yet for drawing firm conclusions in this regard. Fig. 25(b) shows the distributions of permeability on the same section derived from the amount of damage computed in the analysis (equation (20)). It is very interesting to note that, in the laboratory tests on damaged Opalinus clay samples reported by Coll (2005), the values of measured intrinsic permeability were in the range of $10^{-17}$ to $10^{-19} \mathrm{~m}^{2}$, similar to that predicted by the analysis. The extent and evolution of the damaged zone obtained in the 3D calculations can be observed directly by plotting contours of the damage parameter $L$ at different times (Figs 26 and 27). The samples extracted at the end of the experiment 


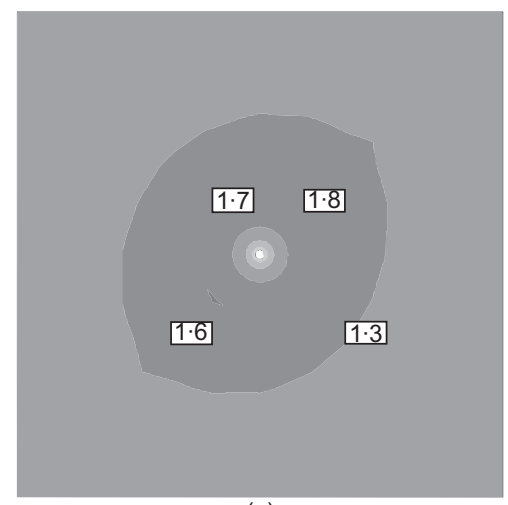

(a)

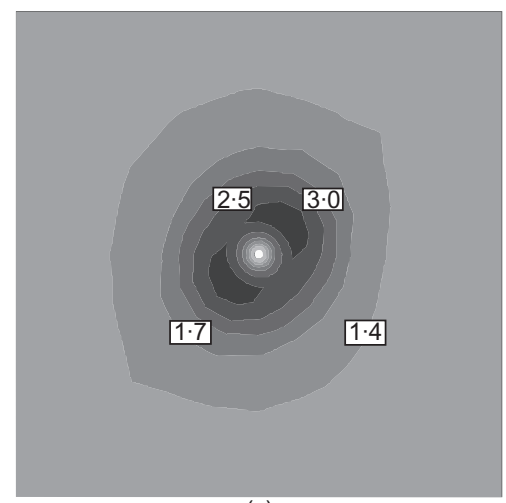

(c)

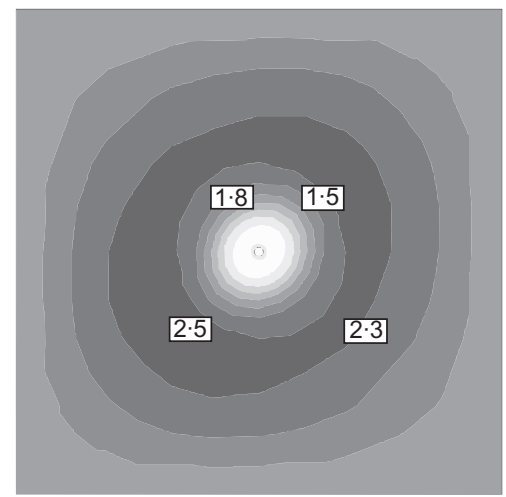

(e)

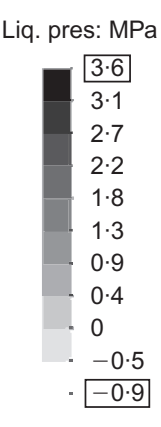

Liq pres: $\mathrm{MPa}$
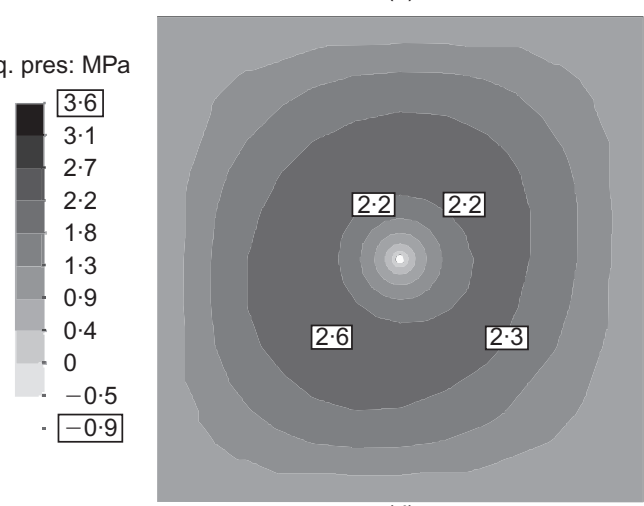

(d)
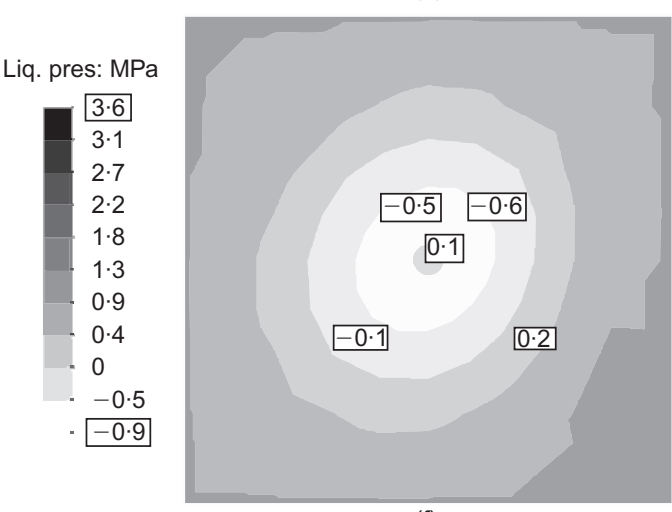

(f)

Fig. 17. Computed contours of equal pore pressure increase (MPa) in cross-section across Heater 2 for: (a) 90 days; (b) 93 days; (c) 110 days; (d) 338 days; (e) 346 days; (f) 501 days

would correspond to the states of the damage zone shown in Figs 26(d) and 27(d).

\section{SENSITIVITY ANALYSIS}

A sensitivity analysis has been performed to examine the effect of various parameters and, in this way, improve the understanding of the system subject to thermo-hydromechanical perturbations. Because many fully coupled THM computations had to be performed, axisymmetry conditions have been accepted, and mechanical non-linearity has been avoided by using a linear mechanical constitutive model as the base case. For space reasons, the effect of variation of individual parameters will be demonstrated by reference to the pore pressure increment evolution in borehole D03 and strain variation of interval 8-9 of borehole D4, the closest to the heater. The thermal field is very similar in all analyses except when thermal conductivity changes are considered.

In the previous section, it has been shown that, although anisotropy effects are certainly noticeable, they are moderate and do not significantly affect the overall behaviour of the experiment examined in this parametric study. Similarly, the chief effect of introducing damage in the constitutive law is a strain increase in the zone close to the heater as a result of stiffness degradation occurring on that region. But, again, the main features of THM behaviour remain largely unchanged. This can be checked in Fig. 28, where the results of analysis A1 (including damage in the constitutive law) and analysis A1-E (linear behaviour) are compared. Thus the use of analysis A1-E as base case is justified.

A selection of the sensitivity analyses performed will be presented, focusing on the most important or uncertain parameters: Young's modulus $E$; Biot coefficient $b$; solid compressibility $\beta_{\mathrm{s}}$; thermal expansion coefficient of solid grains and skeleton $b_{\mathrm{s}}$; thermal conductivity $\lambda$; and intrinsic water permeability $k$.

The value of Young's modulus naturally affects deformations, but also the magnitude of the pore pressure generation due to temperature changes. Analyses have been performed using values of $E$ equal to $11500 \mathrm{MPa}$ and $2000 \mathrm{MPa}$, which go beyond the expected range of reference values (Table 1; 


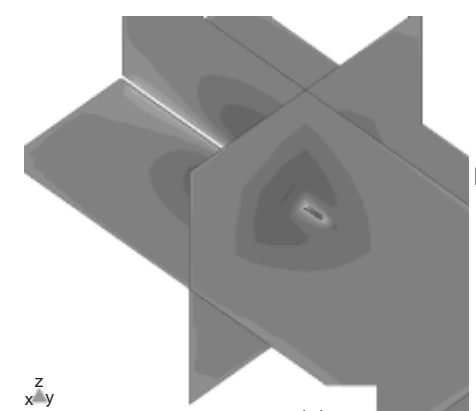

(a)

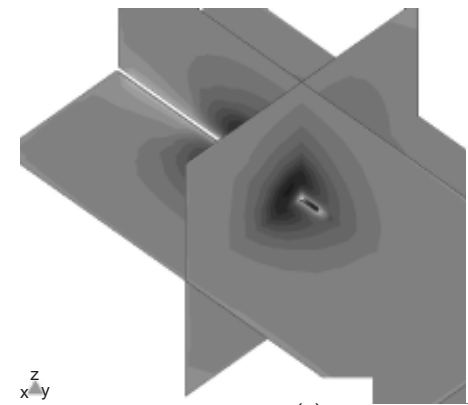

(c)

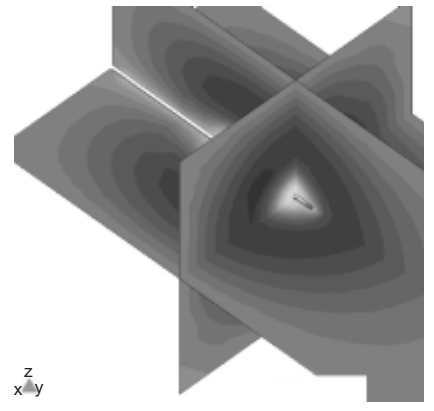

(e)
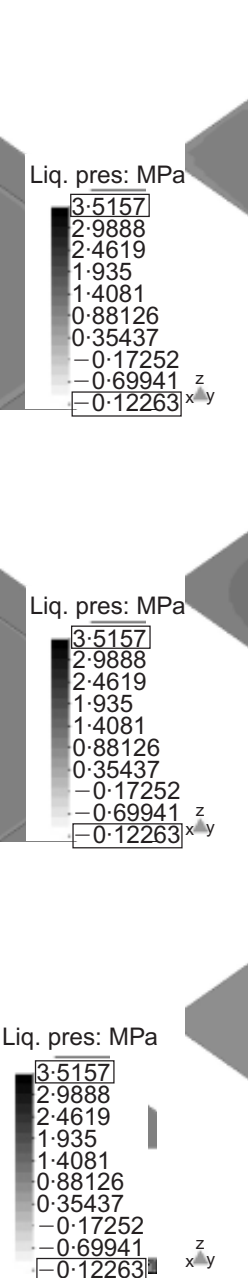

$x$

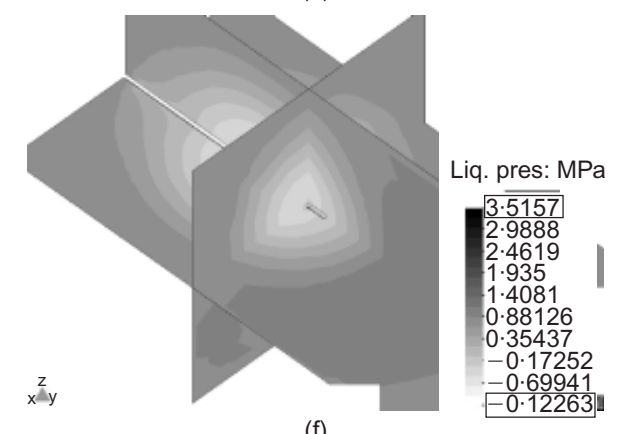

(f)

(b)

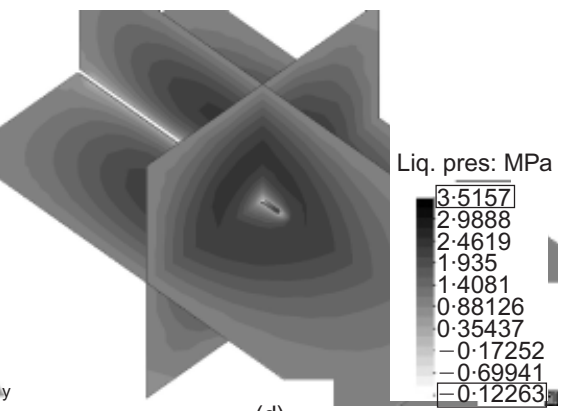

(d)

Fig. 18. Computed contours of equal pore pressure increase (MPa) for: (a) 90 days; (b) 93 days; (c) 110 days; (d) 338 days; (e) 346 days; (f) 501 days

Wileveau, 2005). The results are shown in Fig. 29. As expected, a lower Young's modulus results in a reduced pore pressure generation and larger displacements, but the general pattern of results remains unchanged. Opposite effects are observed when using a larger value of Young's modulus.

As indicated above, there are major uncertainties regarding the actual value of Biot's coefficient $b$ for Opalinus clay. Consequently, additional analyses have been run using values of $b$ equal to 0.4 and 1 . The latter case would, of course, correspond to the assumption of Terzaghi's definition for effective stress. As Fig. 30 shows, the effect of a variation of Biot's coefficient is noticeable but not large. This result also indicates that the major contributor to strains and displacements is thermal expansion.

Solid compressibility $\beta_{\mathrm{s}}$ had to be estimated from mineral composition and compressibility values for individual minerals obtained from the literature. To check on its possible influence on the results two further analyses have been carried out, one with a totally rigid solid mineral and a second one with a higher compressibility. As Fig. 31 indicates, the effects of the variation of this parameter are slight.

The thermal expansion of solid grains $\left(b_{\mathrm{s}}\right)$ and clay skeleton $\left(\alpha_{\mathrm{T}}\right)$ is another uncertain parameter, as laboratory experimental results from different sources have provided a wide range of results (e.g. Gens, 2000; Auvray, 2004; Wileveau, 2005). No significant structural rearrangement is expected during limited thermal expansion, and therefore both parameters are assumed equal. Thermal expansion properties obviously affect thermal strains, but they also influence pore pressure generation. Consequently, Fig. 32 shows a small effect on computed pore pressures but a very large effect on the computed strains. It is more evidence of the dominance of thermally generated strains and displacements.

The low permeability of the clay ensures that heat transport by advection is negligible, and therefore the only significant heat transport mechanism is heat conduction. Consequently, a variation in thermal conductivity $\lambda$ must affect the temperature field directly. This is immediately apparent in the results shown in Figs 33(a) and 33(b). The temperature in the clay/heater interface varies significantly with the value of $\lambda$ (Fig. 31(a)), the base case parameter giving a good estimation of the recorded temperature. The computed effects on pore pressure (Fig. 33(c)) and strains (Fig. 33(d)) are a consequence of the differences in temperature.

The mechanism underlying the hydraulic behaviour in the clay is a competition between the generation of pore pressures by the differential thermal expansion of liquid and solid and the dissipation of pore pressures, the rate of which is controlled mainly by the value of water permeability. Therefore variations of intrinsic water permeability $k$ are bound to have a profound effect on test behaviour, especially concerning the hydraulic aspects. Fig. 34 shows the results of sensitivity analyses where the values of intrinsic per- 


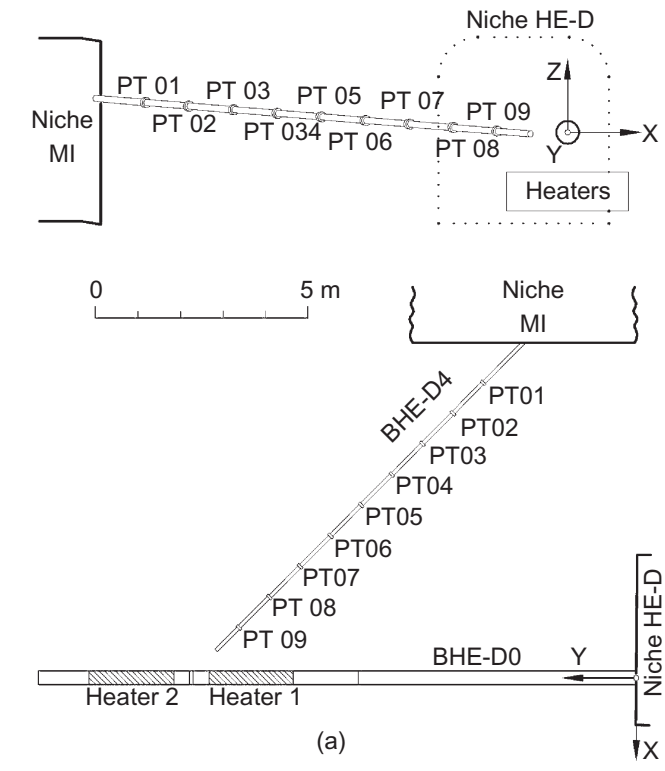

Niche HE-D
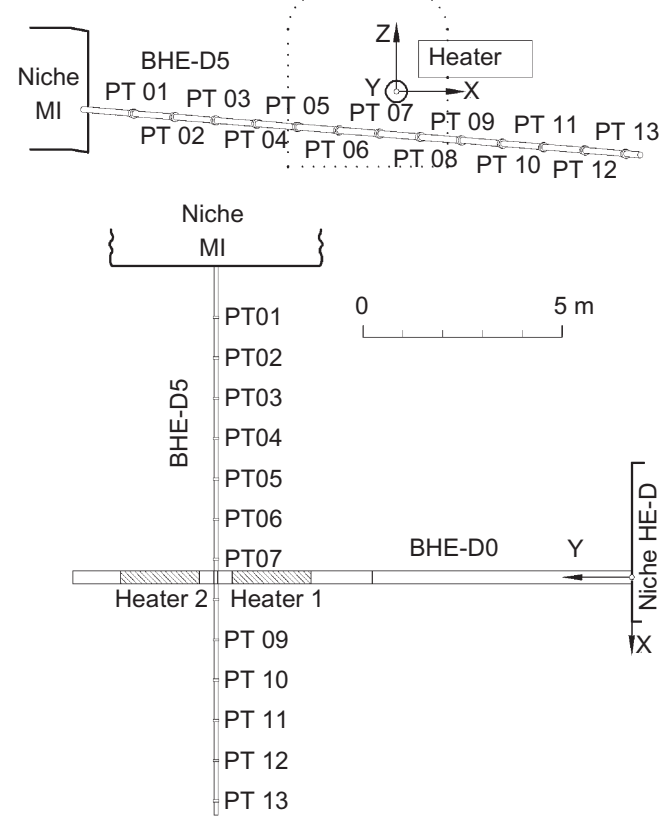

(b)

Fig. 19. Plan and elevation of (a) borehole D4 and (b) borehole D5 for displacement measurements

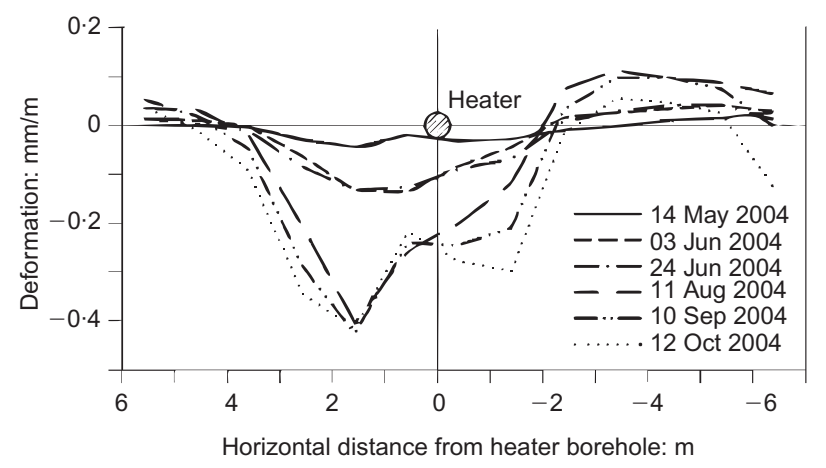

Fig. 20. Distributions of deformation measured at different times in borehole D5, drilled approximately perpendicular to main borehole

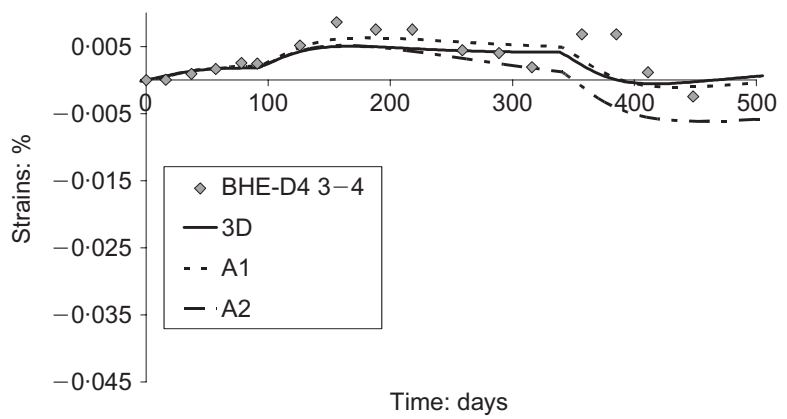

(a)

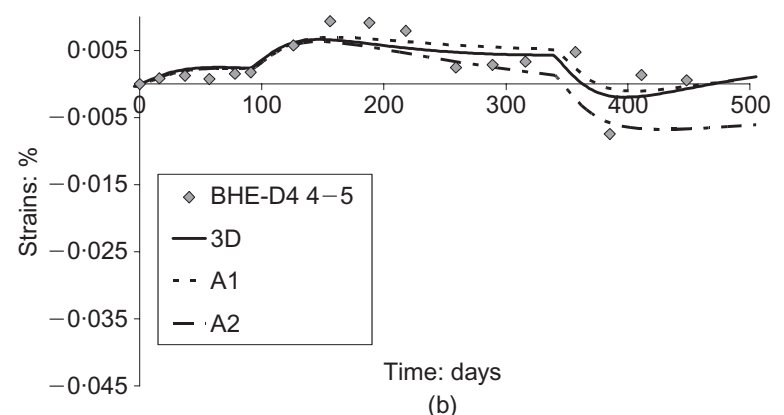

(b)

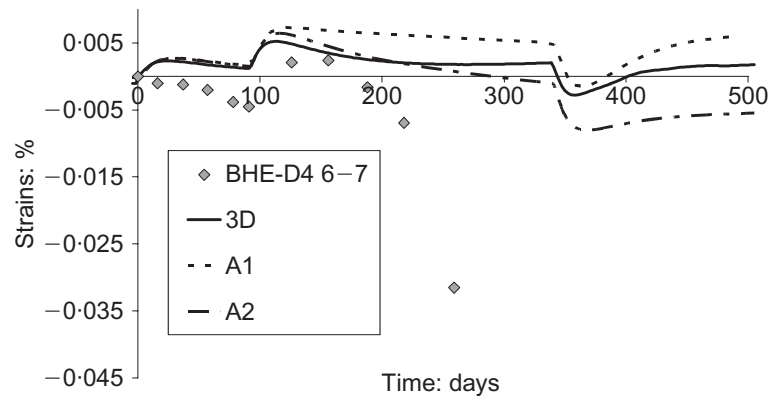

(c)

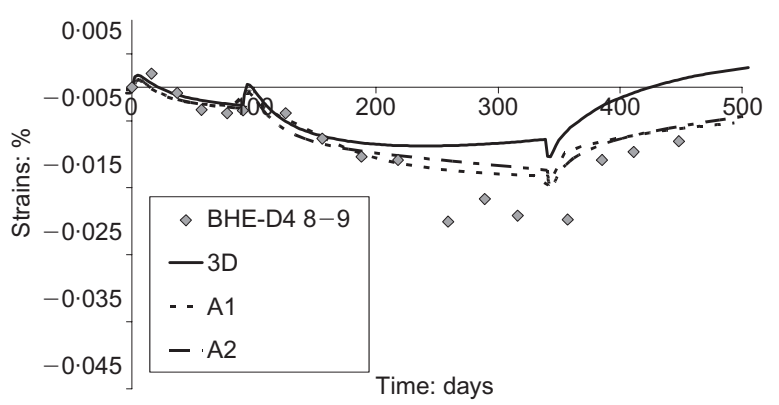

(d)

Fig. 21. Evolution of strain increments at various points in the clay: observed and computed results. Borehole D4

meability have been varied by an order of magnitude (from $10^{-19} \mathrm{~m}^{2}$ to $10^{-20} \mathrm{~m}^{2}$ ), staying within the range of reference values of Table 1. It is apparent that the effect on generated pore pressures is very large, and their subsequent dissipation also affects the predicted strains considerably. Because of the importance of this parameter in the global behaviour of the test, a further two analyses have been performed to represent practically undrained and drained conditions. To this end intrinsic permeabilities of $10^{-23} \mathrm{~m}^{2}$ and $10^{-16} \mathrm{~m}^{2}$ have been used, well beyond the range of measured permeabilities. The results are shown in Fig. 35. In the very low- 


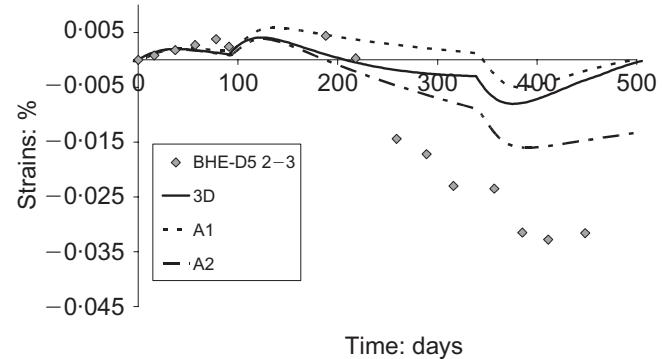

(a)

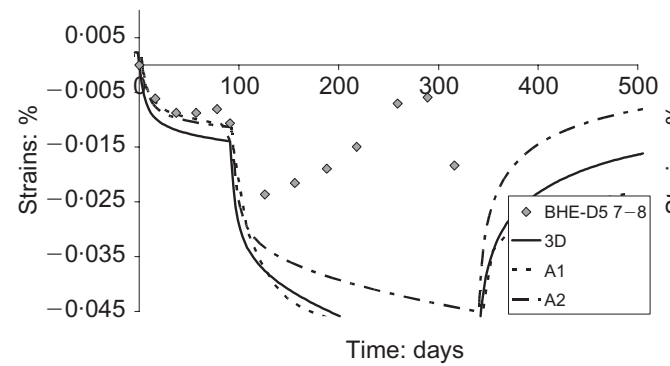

(c)

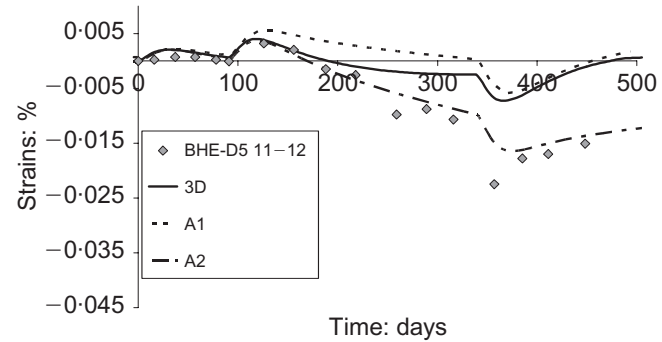

(e)

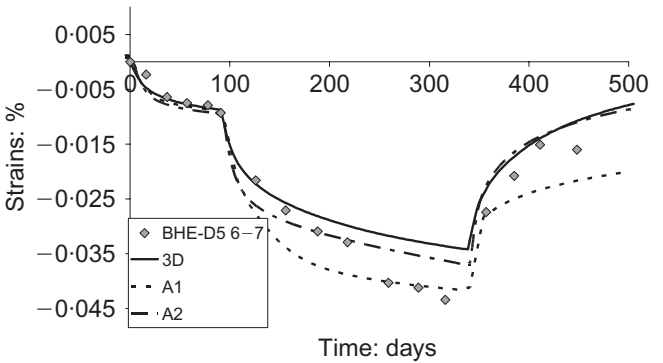

(b)

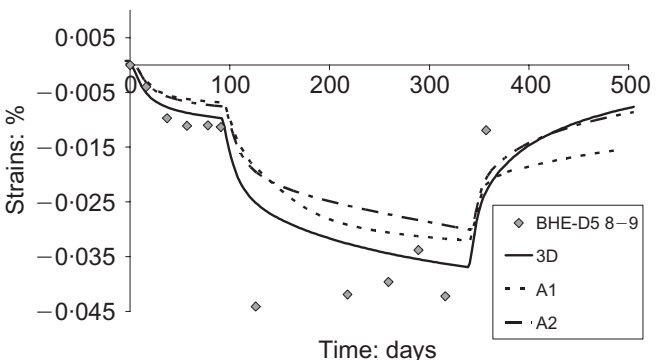

(d)

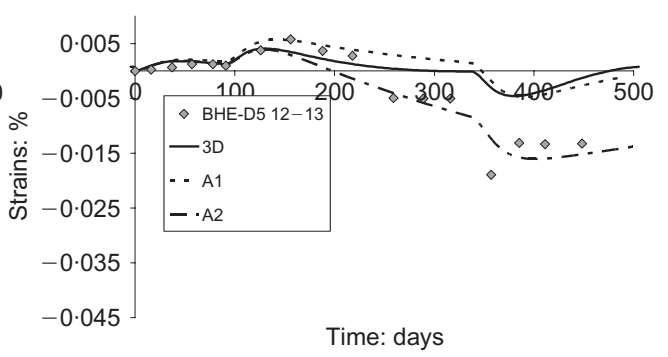

(f)

Fig. 22. Evolution of strain increments at various points in the clay: observed and computed results. Borehole D5

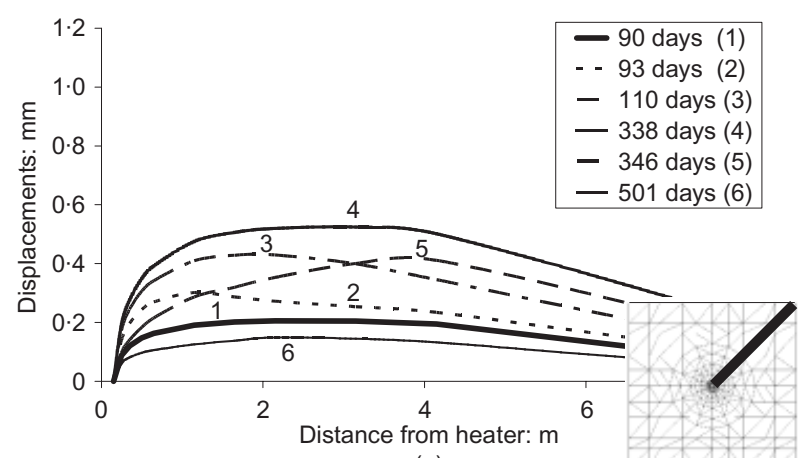

(a)

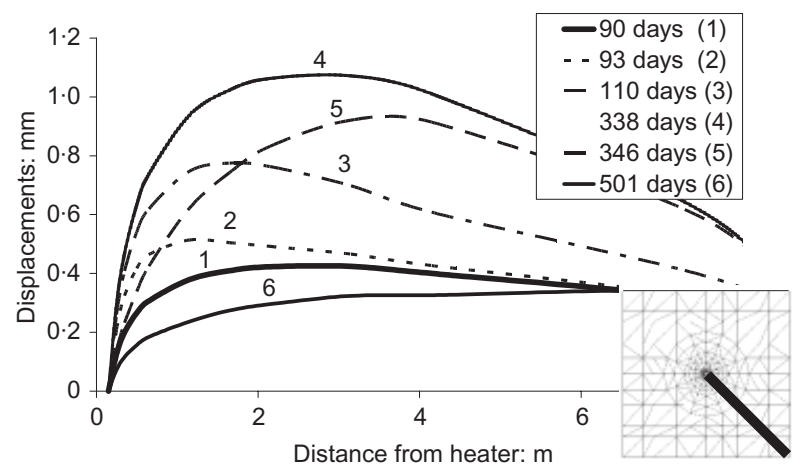

(b)

Fig. 23. Computed radial displacement distributions at various times on a section between the two heaters: (a) bedding plane direction; (b) perpendicular to bedding plane direction

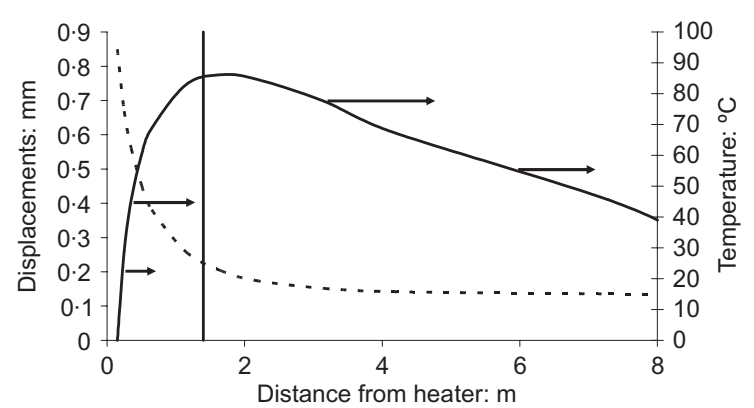

Fig. 24. Computed displacement and temperature distributions at 110 days in cross-section of Heater 2, in direction perpendicular to bedding

permeability case there is an extremely large rise of pore pressures, which follows the temperature evolution. Dissipation is practically negligible: that is, undrained conditions prevail. By contrast, in the very large-permeability case no pore pressure generation is observed, as pore pressure dissipation dominates throughout: that is, drained conditions occur. The different hydraulic conditions result in noticeable differences of strain development.

\section{CONCLUSIONS}

Opalinus clay is a stiff layered Mesozoic clay of marine origin. When saturated stiff clays are subjected to thermal loading, they may develop a strong pore pressure response. 


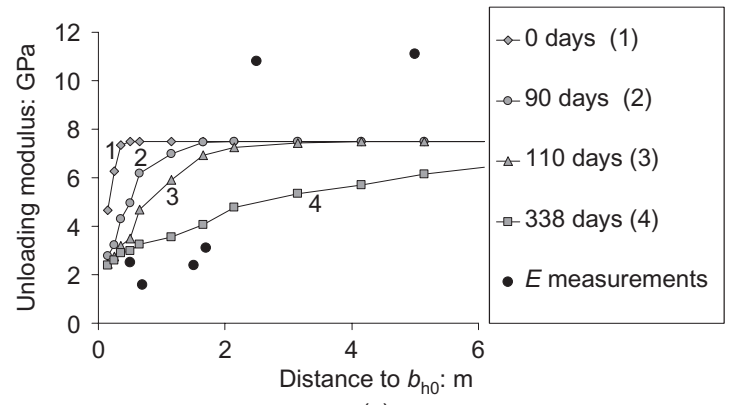

(a)

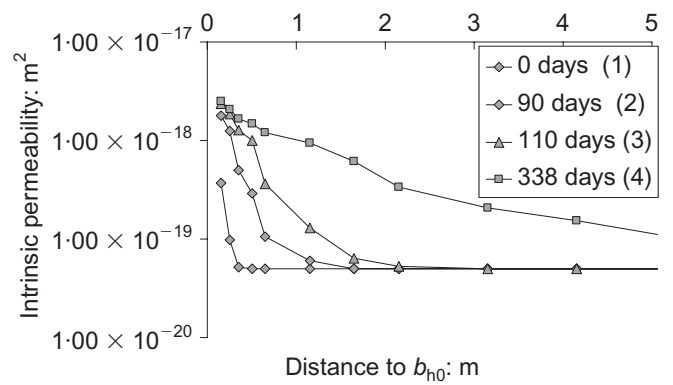

(b)

Fig. 25. (a) Distribution of unloading elastic modulus at various times on section perpendicular to Heater 2; elastic moduli measured on samples taken at end of test are indicated. (b) Distribution of computed permeability at various times on section perpendicular to Heater 2
In turn, the generated pore pressures will impact on subsequent thermo-hydro-mechanical behaviour. The performance of a heating test in the Mont Terri underground laboratory has provided the opportunity to observe in situ the development of the coupled THM behaviour in this type of material. A priori, the strongly bedded nature of the clay suggested that anisotropy effects could be significant.

Performance of three-dimensional coupled THM analysis has proved very useful in providing a structured framework for interpretation. A 3D simulation has allowed the incorporation of anisotropic material properties and anisotropic in situ stress state. By comparing the results of the $3 \mathrm{D}$ computations with those of axisymmetric analyses, it is possible to conclude that the anisotropic effects are certainly noticeable although not large. The mechanical behaviour of the material has been described by a constitutive model that explicitly considers bonding and its subsequent damage. It is of interest to note that the predicted damaged zone by thermal effects appears to be quite consistent with independent clay stiffness determinations performed after the test. Overall, the theoretical formulation adopted and the $3 \mathrm{D}$ analysis performed have been able to provide a satisfactory reproduction of in situ test observations, even from a quantitative point of view.

A sensitivity analysis has also been carried out to assist in the interpretation of the test and to achieve an enhanced understanding of the phenomena involved. The intensity of cross-coupling between the different aspects of the problem

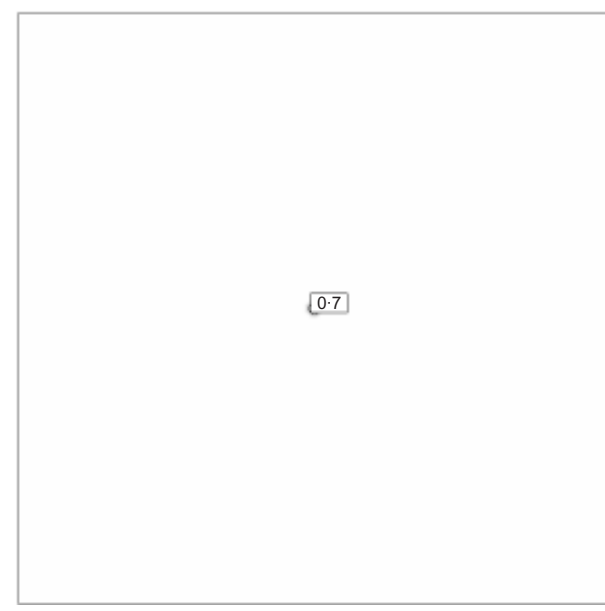

(a)

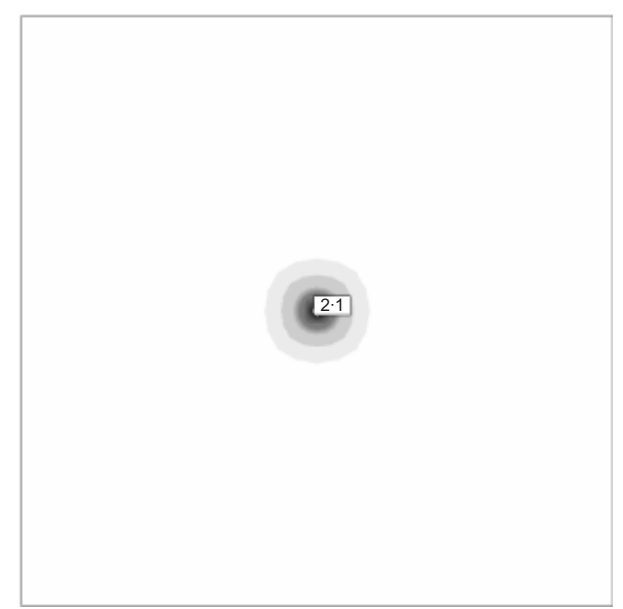

(c)
Damage parameter

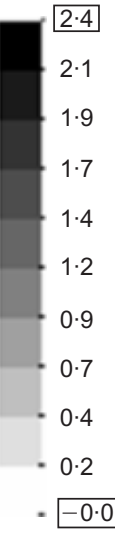

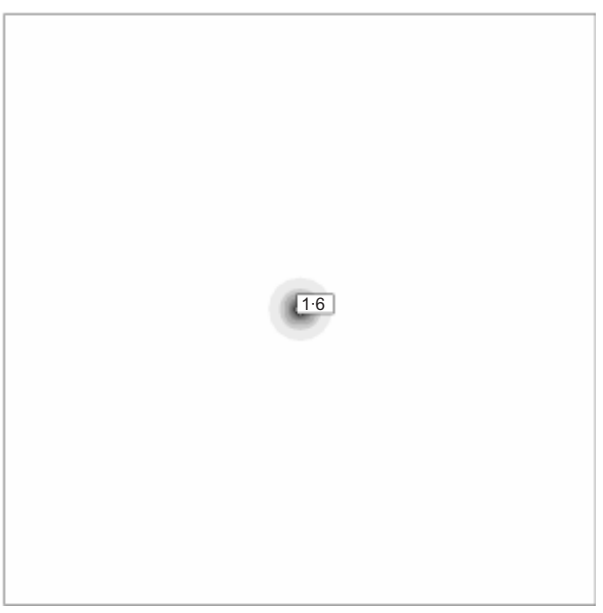

(b)

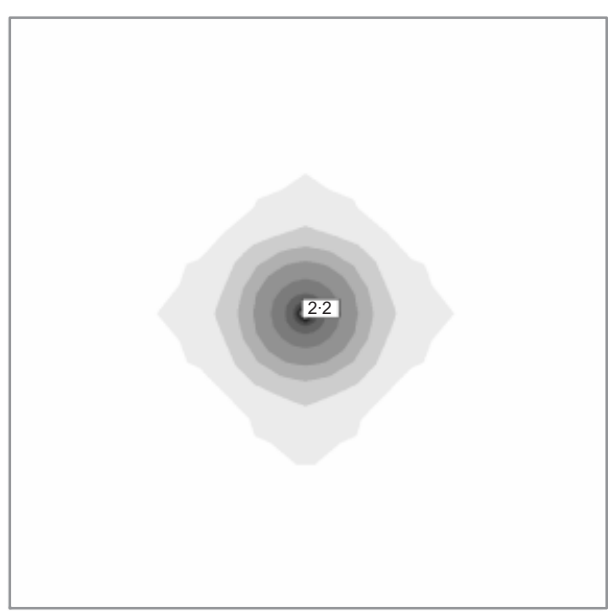

(d)

Fig. 26. Contours of damage parameter $L$ in cross-section across Heater 2 at various times: (a) before heating starts (day 0); (b) end of first stage of heating (day 90); (c) pore pressure maxima (110 days); (d) end of test (508 days) 


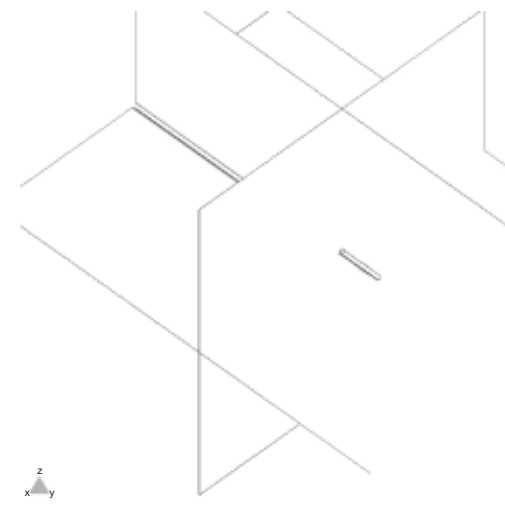

(a)

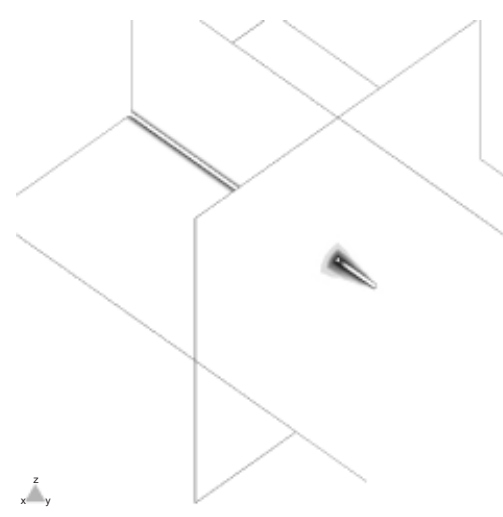

(c)

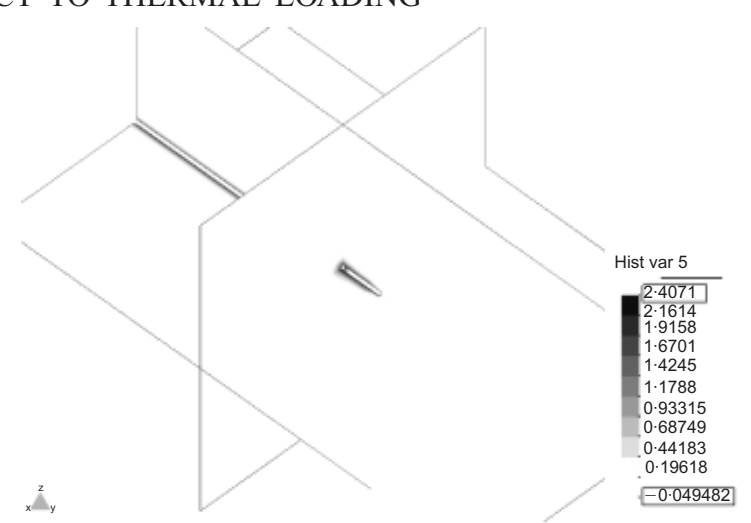

(b)

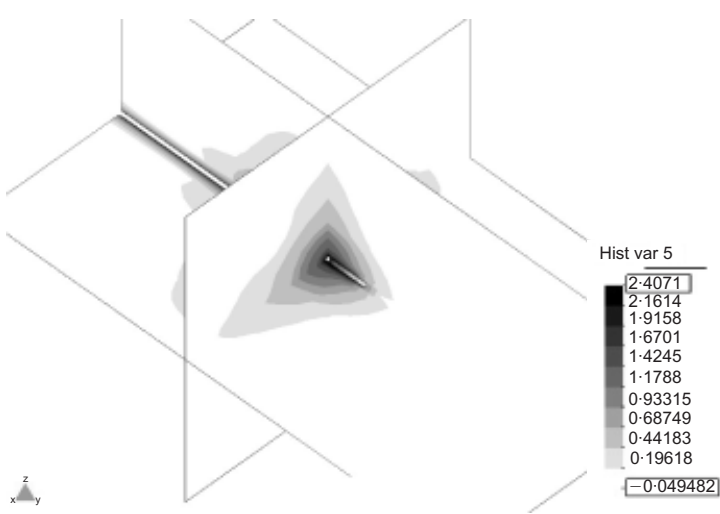

(d)

Fig. 27. Three-dimensional view of contours of damage parameter $L$ at various times: (a) before heating starts (day 0); (b) end of first stage of heating (day 90); (c) pore pressure maxima (110 days); (d) end of test (508 days)

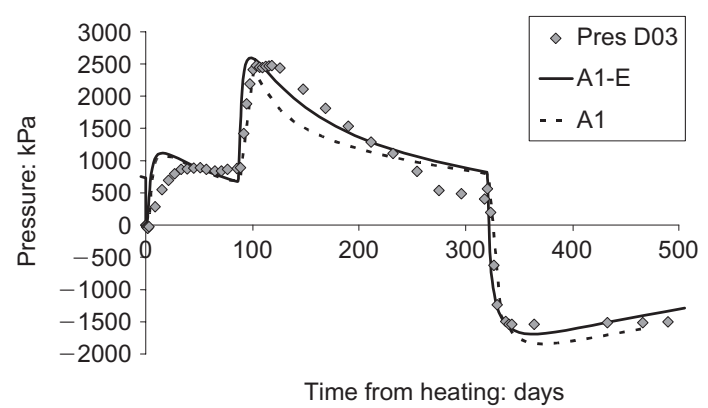

(a)

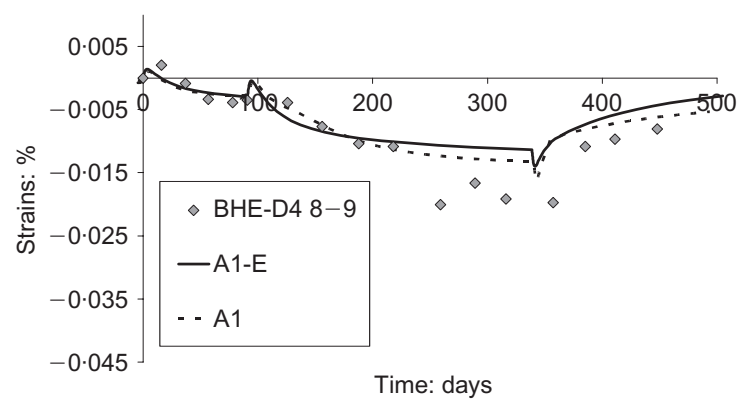

(b)

Fig. 28. Comparison of computed results of analysis A1 (considering damage) and A1-E (linear clay behaviour) referring to: (a) pore pressure evolution; (b) strain evolution

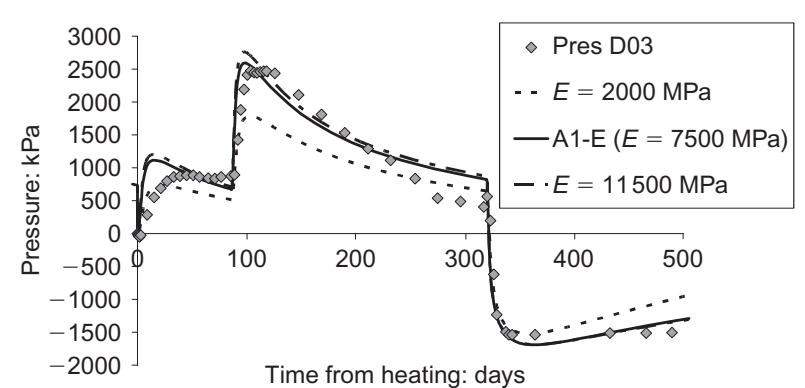

(a)

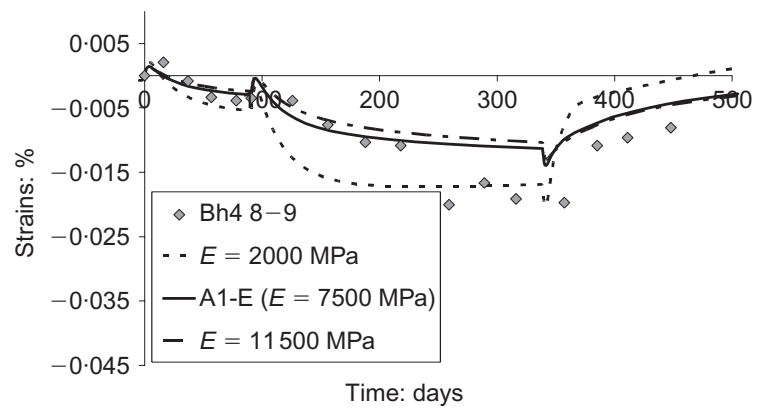

(b)

Fig. 29. Effect of variation of Young's modulus on: (a) pore pressure evolution; (b) strain evolution

turns out to be very variable, and can be organised in a hierarchical manner, as follows.

(a) The strongest coupling is found from thermal to hydraulic and mechanical behaviour. Pore pressure 


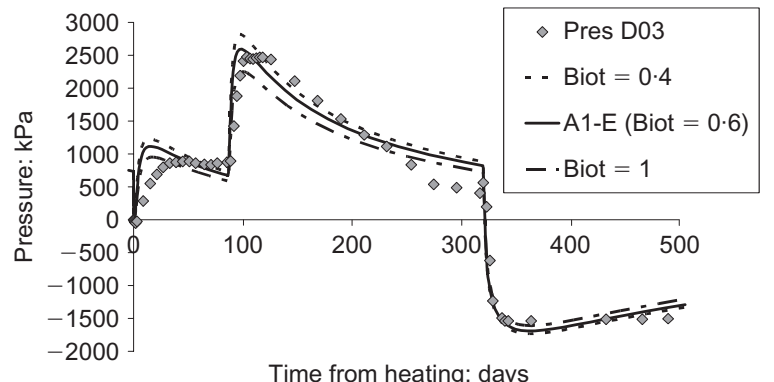

(a)

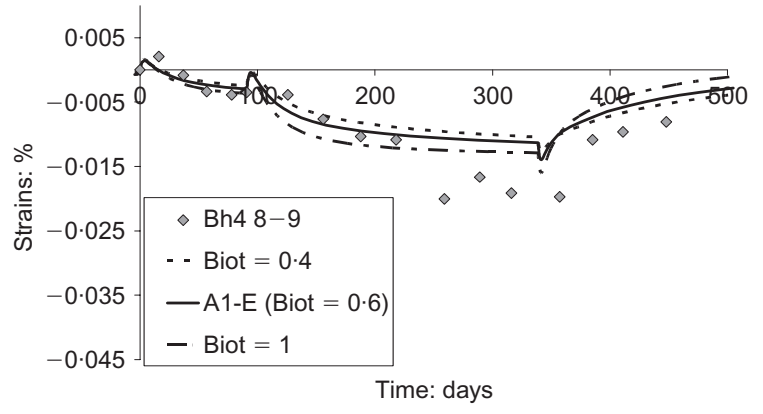

(b)

Fig. 30. Effect of variation of Biot's coefficient on: (a) pore pressure evolution; (b) strain evolution

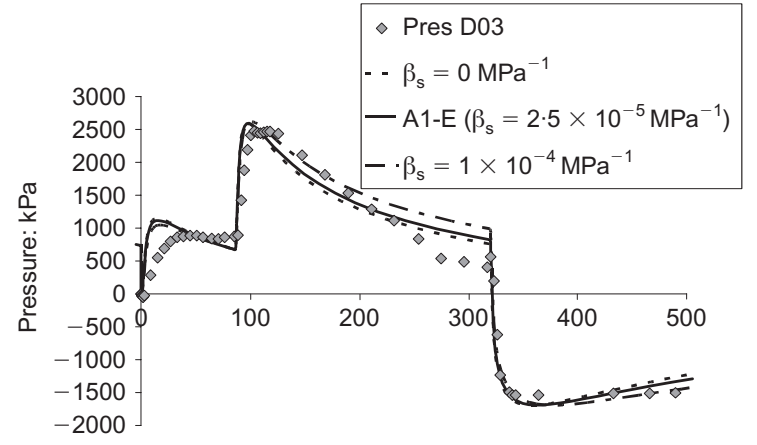

Time from heating: days

(a)

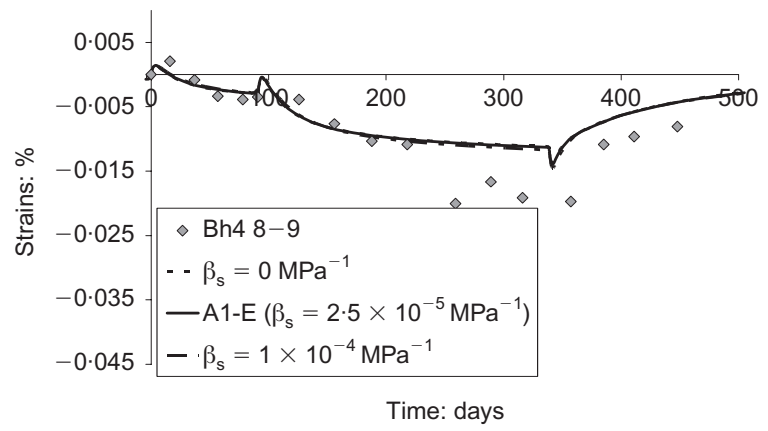

(b)

Fig. 31. Effect of variation of solid phase compressibility on: (a) pore pressure evolution; (b) strain evolution

generation is controlled primarily by temperature increase, and the largest contributor to deformation and displacements is thermal expansion.

(b) Significant but more moderate effects are identified

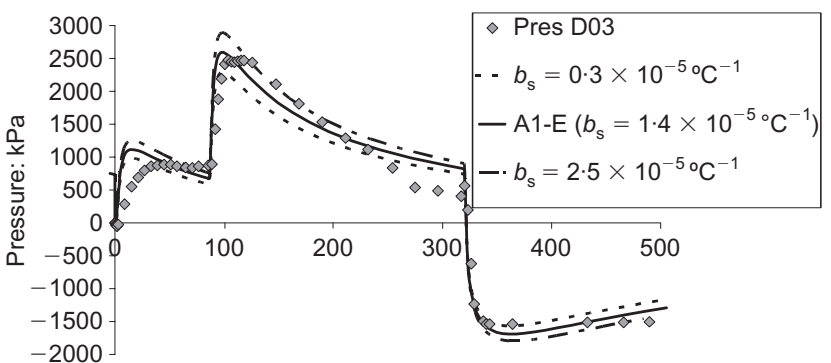

Time from heating: days

(a)

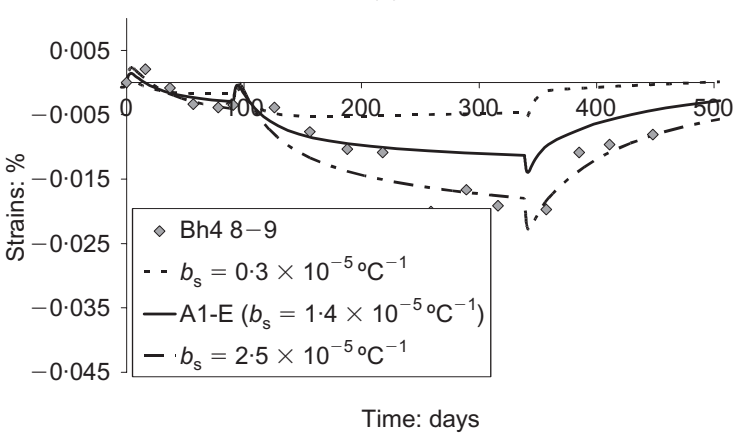

(b)

Fig. 32. Effect of thermal expansion coefficient on: (a) pore pressure evolution; (b) strain evolution

from the coupling of hydraulic to mechanical behaviour. The dissipation of pore pressures induces additional displacements and strains, but, because of the large clay stiffness, they are smaller than thermally induced deformations.

(c) In principle, mechanical damage could impact on the hydraulic results because of the development of higher permeability owing to material damage. However, the damaged zone appears to be very limited in this case, and the effects do not seem to be very significant.

(d) There is no noticeable coupling from hydraulic to thermal behaviour. Practically all heat transport is by conduction, and the thermal conductivity of the material does not change, as the material remains saturated throughout.

(e) Coupling from mechanical to thermal behaviour is negligible. The changes of clay porosity are so slight that they do not affect thermal conductivity. In addition, mechanical energy dissipation is insignificant in this non-isothermal case.

\section{ACKNOWLEDGEMENTS}

The work presented in this paper was financially and technically supported by the Agence Nationale pour la gestion des déchets radioactifs (ANDRA) of France. The authors also want to acknowledge the support of the European Commission via a Marie Curie Fellowship awarded to Benoit Garitte within the framework of the Mechanics of Unsaturated Soils for Engineering Research Training Network. The contribution of the Spanish Ministry of Education and Science through research grant BIA2005-05801 is also acknowledged. The authors are grateful to J. Pineda for providing the data from the experimental determination of Opalinus clay stiffness. 


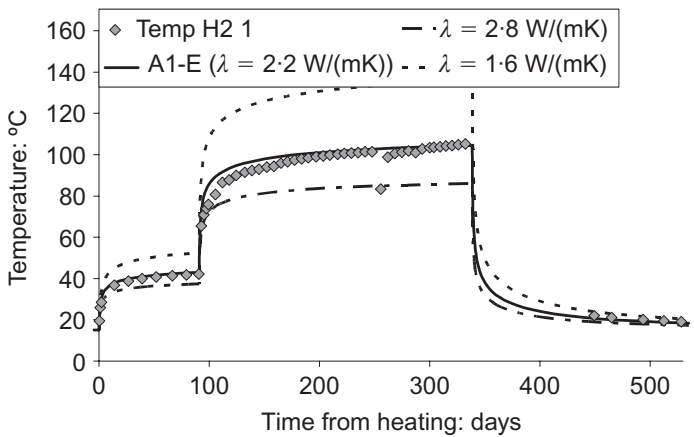

(a)

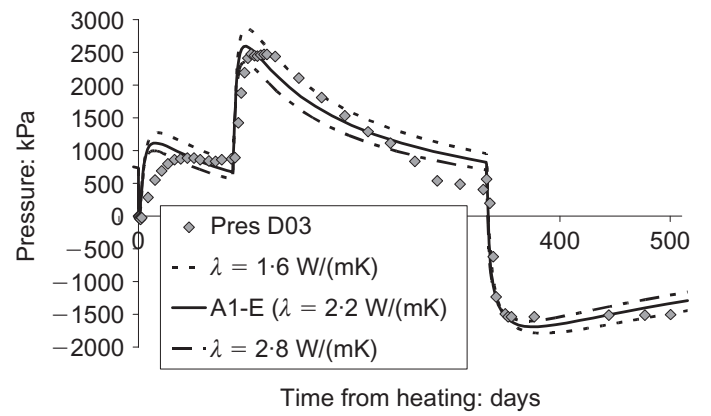

(c)

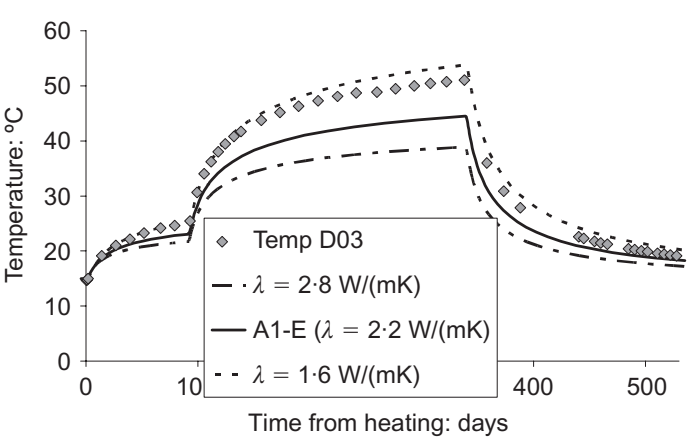

(b)

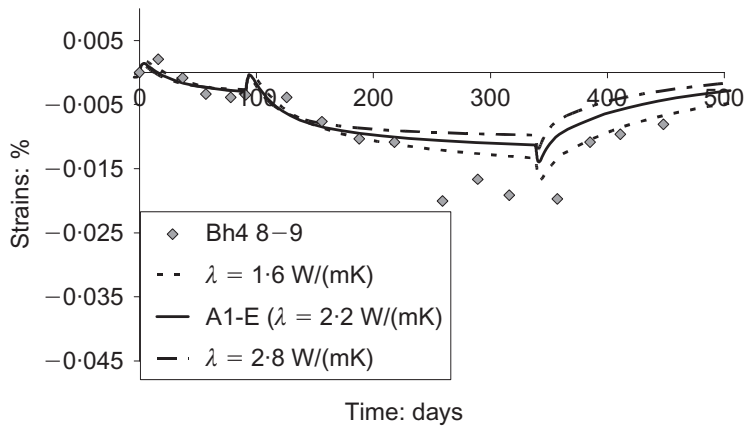

(d)

Fig. 33. Effect of thermal conductivity on: (a) temperature evolution on the clay/heater interface; (b) temperature evolution of borehole D03; (c) pore pressure evolution of borehole D03; (d) strain evolution of interval 8-9 of borehole D4

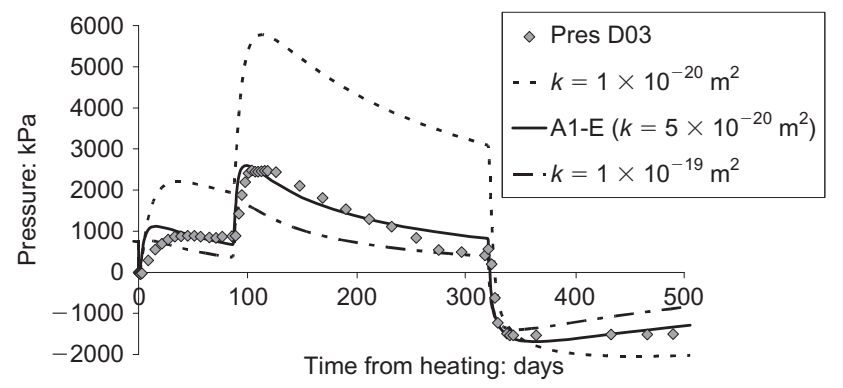

(a)

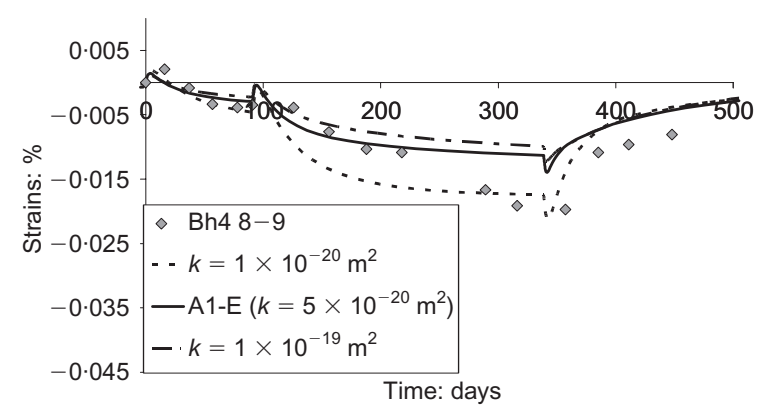

(b)

Fig. 34. Effect of intrinsic permeability on: (a) pore pressure evolution; (b) strain evolution. Permeability parameters in the range of reference values

\section{REFERENCES}

ANDRA (2005). Dossier 2005, Référentiel du site Meuse/Haute Marne, Tome 2, Report CRPADS040022_B. Chatenay-Malabry: ANDRA.

Auvray, C. (2004). Thermomechanical tests on Opalinus clays of the Mont Terri, ANDRA Report C.RP.OENG.04-0239. Chatenay-Malabry: ANDRA.

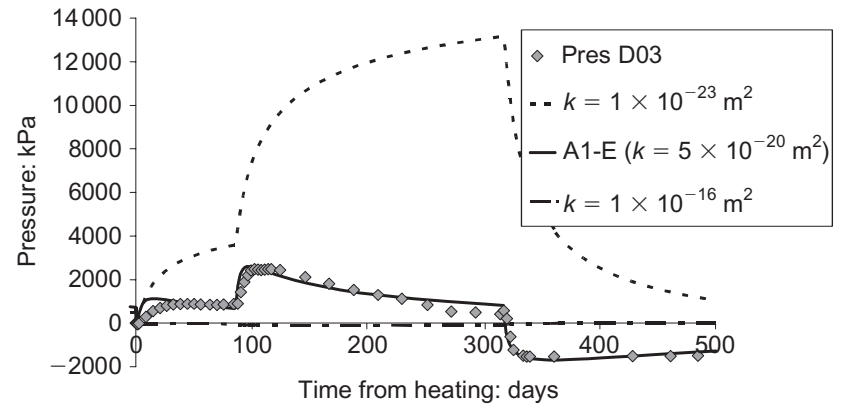

(a)

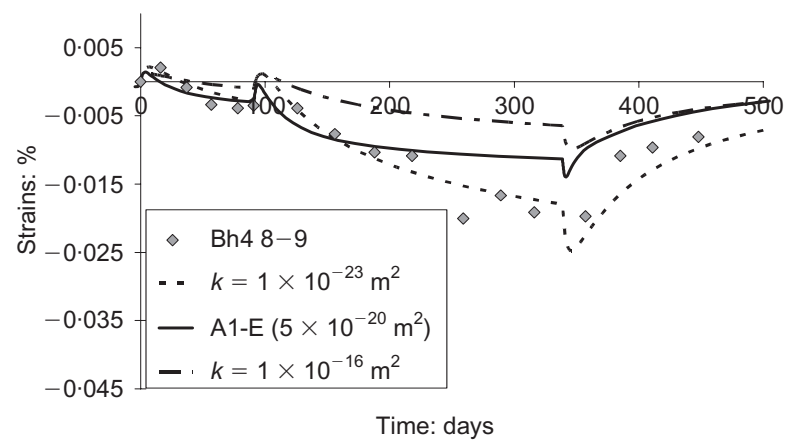

(b)

Fig. 35. Effect of intrinsic permeability on: (a) pore pressure evolution; (b) strain evolution. Undrained and drained conditions

Bai, M. \& Abousleiman, Y. (1997). Thermoporoelastic coupling with application to consolidation. Int. J. Numer. Anal. Methods Geomech. 21, No. 2, 121-132.

Baldi, G., Hueckel, T., Peano, A. \& Pellegrini, R. (1991). Developments in modelling of thermo-hydro-geomechanical behaviour of Boom Clay and clay-based buffer materials. ISMES, Final report, EUR 13365/1. Luxembourg: ISMES. 
Bastiaens, W., Bernier, F. \& Li, X. L. (2006). An overview of longterm HM measurements around HADES URF. In EUROCK 2006: Multiphysics coupling and long-term behaviour in rock mechanics (eds Van Cotthem, A., Charlier, R., Thimus, J. F. and Tshibangu, J. P.), pp. 15-25. London: Taylor \& Francis.

Bernier, F. \& Neerdael, B. (1996). Overview of in situ thermomechanical experiments in clay: concept, results and interpretation. Engng Geol. 41, Nos 1-4, 51-64.

Bernier, F., Volckaert, G., Alonso, E. \& Villar, M. (1997). Suctioncontrolled experiments on Boom Clay. Engng Geol. 47, No. 4, 325-338.

Bock, H. (2001). RA experiment. Rock mechanics analyses and synthesis: Data report on rock mechanics, Technical Report 2000-02. Mont Terri Project.

Booker, J. R. \& Savvidou, C. (1985). Consolidation around a point heat source. Int. J. Numer. Anal. Methods Geomech. 9, No. 2, 173-184.

Bossart, P., Meier, P. M., Moeri. A., Trick, T. \& Mayor, J.-C. (2002). Geological and hydraulic characterisation of the excavation disturbed zone in the Opalinus clay of the Mont Terri rock laboratory. Engng Geol. 66, Nos 1-2, 19-38.

Carol, I., Rizzi, E. \& Willam, K. (2001). On the formulation of anisotropic elastic degradation. I. Theory based on a pseudologarithmic damage tensor rate. Int. J. Solids Struct. 38, No. 4, 491-518.

Coll, C. (2005). Endommagement des roches argileuses et perméabilité induite au voisinage d'ouvrages souterrains. Doctoral thesis, Université Joseph Fourier, Grenoble, France.

Cordebois, J. P. \& Sidoroff, F. (1982). Endommagement anisotrope en élasticité et plasticité. J. de Mécanique Théorique et Appliquée, Numéro Spécial, 45-60.

Croisé, J., Schlickenrieder, L., Marschall P., Boisson J.-Y., Vogel, P. \& Yamamoto, S. (2004). Hydrogeological investigations in a low permeability claystone formation: the Mont-Terri Rock Laboratory. Phys Chem. of the Earth 29, No. 1, 3-15.

De Bruyn, D. \& Labat, S. (2002). The second phase of ATLAS: the continuation of a running THM test in the HADES underground research facility at Mol. Engng Geol. 64, Nos 2-3, 309-316.

Gens, A. (2000). HE experiment: Complementary rock laboratory tests, Technical Note TN 2000-47. Mont Terri Project.

Gens, A. (2003). The role of geotechnical engineering in nuclear energy utilisation (Special Lecture). Proc. 13th Eur. Conf. Soil Mech. Geotech. Engng, Prague 3, 25-67.

Gens, A. \& Olivella, S. (2000). Non isothermal multiphase flow in deformable porous media: Coupled formulation and application to nuclear waste disposal. In Developments in theoretical geomechanics: The John Booker Memorial Symposium (eds D. W. Smith and J. P. Carter), pp. 619-640. Rotterdam: Balkema.

Gens, A., Vaunat, J., Garitte, B. \& Wileveau, Y. (2006). Response of a saturated mudstone under excavation and thermal loading. In EUROCK 2006: Multiphysics coupling and long-term behav- iour in rock mechanics (eds Van Cotthem, A., Charlier, R., Thimus, J. F. and Tshibangu, J. P.), pp. 35-44. London: Taylor \& Francis.

Harrington, J. F., Horseman, S. T. \& Noy, D. J. (2001). Swelling and osmotic flow in a potential host rock. Proc. 6th Int. Workshop on Key Issues in Waste Isolation Research, Paris, 169-188.

Horseman, S. T., Winter, M. G. and Entwistle, D. C. (1987). Geotechnical characterization of boom clay in relation to the disposal of radioactive waste, EUR 10987. Luxembourg: Commission of the European Communities.

Kanj, M. \& Abousleiman, Y. (2005). Porothermoelastic analyses of anisotropic hollow cylinders with applications. Int. J. Numer. Anal. Methods Geomech. 29, No. 2, 103-126.

Katsube, N. (1988). The anisotropic thermo-mechanical constitutive theory for fluid-filled porous materials with solid/fluid outer boundaries. Int. J. Solids Struct. 24, No. 4, 375-380.

Kurashige, M. (1989). A thermoelastic theory of fluid-filled porous materials. Int. J. Solids Struct. 25, No. 9, 1039-1052.

Martin, C. D. \& Lanyon, G. W. (2003) Measurement of in situ stress in weak rocks at Mont Terri Rock Laboratory, Switzerland. Int. J. Rock Mech. Mining Sci. 40, Nos 7-8, 1077-1088

Olivella, S., Carrera, J., Gens, A. \& Alonso, E. E. (1994). Nonisothermal multiphase flow of brine and gas through saline media. Trans. Porous Media 15, No. 3, 271-293.

Picard, J. M., Bazargan, B. \& Rousset, G. (1994). Essai thermohydro-mécanique dans une argile profonde: Essai CACTUS, CEC Report EUR 15482 FR. Luxembourg: CEC.

Schaeren, G. \& Norbert, J. (1989). Tunnel du Mont Terri et du Mont Russelin. La traversée des roches à risques: marnes et marnes à anhydrite, SIA-Dokumentation D037, La traversée du Jura - Les projets des nouveaux tunnels. Zürich: Swiss Society of Engineers and Architects (SIA).

Thury, M. \& Bossart, P. (1999) The Mont Terri rock laboratory, a new international research project in a Mesozoic shale formation, in Switzerland. Engng Geol. 52, Nos 3-4, 347-359.

Vaunat, J. \& Gens, A. (2003). Numerical modelling of an excavation in a hard soil/soft rock formation using a coupled damage/ plasticity model. Proc. 7th Int. Conf. on Computational Plasticity COMPLAS 2003, Barcelona (CD-ROM).

Wang, Y. \& Papamichos, E. (1999). Thermal effects on fluid flow and hydraulic fracturing from wellbores and cavities in low permeability formations. Int. J. Numer. Anal. Methods Geomech. 23, No. 15, 1819-1834.

Wermeille, S. \& Bossart, P. (1999). In situ stresses in the Mont Terri Region: Data compilation, Technical Report 99-02. Mont Terri Project.

Wileveau, Y. (2005). THM behaviour of host rock (HE-D) experiment: Progress report. Part 1, Technical Report TR 2005-03. Mont Terri Project.

Zimmerman, R. W. (2000). Coupling in poroelasticity and thermoelasticity. Int. J. Rock Mech. Min. Sci. 37, Nos 1-2, 79-87. 